\title{
Optimización de plantas hidroeléctricas para abas- tecer poblaciones rurales en Honduras
}

\author{
Alejandro Tapia Córdoba'
}

Resumen: El acceso a la electricidad sigue siendo un desafío para una gran parte de la población de Honduras. En un país con una población rural fuertemente diseminada en pequeñas comunidades, la naturaleza montañosa de la Cordillera Centroamericana se traduce en limitaciones para extender el sistema eléctrico. Desde 2003, la Fundación Hondureña de Investigación Agrícola (FHIA) combate estas dificultades instalando sistemas hidráulicos en pequeñas comunidades rurales. Sin embargo, la limitación provoca un amplio margen de mejora de estos sistemas rudimentarios. Este trabajo presenta una estrategia de mejora y optimización matemática de la metodología tradicional de diseño, permitiendo aprovechar al máximo los recursos naturales de estas comunidades. La nueva metodología se ha aplicado con éxito en una comunidad piloto. Las ventajas de esta metodología han sido tales que ha sido implementada por los técnicos de FHIA para ser replicada en las intervenciones sucesivas.

Palabras clave: Energía renovable, pobreza energética, microhidrocentrales, Honduras.

Fecha de recepción: 4 de marzo de 2020².

Fecha de admisión definitiva: 24 de abril de 2020.

\footnotetext{
' Profesor, Escuela Técnica Superior de Ingeniería, Universidad Loyola Andalucía.

${ }^{2}$ Investigación $2^{\circ}$ clasificada en el Premio Universidad Loyola a la Investigación en Desarrollo 2020.
} 
Optimisation of hydro-electric plants to support rural populations in Honduras

Abstract: Access to electricity is a challenge for a large part of the population of Honduras. In a country where the rural population is living in small, widely dispersed communities, the mountainous nature of the Central American Cordillera means there are limits to the extent of the electrical system. Since 2003 the Honduras Foundation for Agricultural Research (FHIA) has been confronting these difficulties, installing water system in small communities. However, these limits mean there is still plenty of room for improvement in these rudimentary systems. This paper presents an improvement and mathematical optimisation strategy for the traditional design methodology, which allows for the most effective use of available natural resources. The new methodology has been applied successfully in one pilot community. The advantages of it have been such that it has been implemented by the FHIA in order to be reproduced in future interventions.

Key words: renewable energy; energy poverty; micro hydro power plants; Honduras.

\section{Optimisation des centrales hydro-éléctriques pour approvisionner les populations rurales en Honduras}

Résumé: L'accès à l'électricité reste un défi pour une grande partie de la population en Honduras. Dans un pays dont la population rurale est fortement dispersée dans de petites communautés, la nature montagneuse de la Cordillère Centro-Américaine signifie qu'ilya des limites à l'extension du système électrique. Depuis 2003, la Fondation Hondurien pour la Recherche Agricole (FHIA) lutte contre ces difficultés en installant des systèmes d'eau dans les petites communautés rurales. Cependant, la limitation entraine unegrande marge d'amélioration de ces systèmes rudimentaires. Cetravail présente une stratégie pour l'amélioration et l'optimisation mathématique de la méthodologie de conception traditionnelle, permettant I'utilisation maximale des ressources naturelles de ces communautés. La nouvelle méthodologie a été appliquée avec succès dans une communauté pilote. Les avantages de cette méthodologie ont été tels qu'elle a été mise en œuvre par les techniciens du FHIA pour être reproduite lors d'interventions successives.

Mots clé: énergie renouvelable; pauvreté énergétique; micro-hydro centrales; Honduras.

Agradecimientos: El autor quisiera agradecer a Fabio Gómez-Estern y a Pablo Millán por supervisar esta investigación. Y por supuesto a los miembros de la Fundación ETEA, especialmente a Michela Accerenzi y a María José Vázquez, por haber hecho posible un proyecto tan motivador.

\section{Introducción}

El acceso universal a la energía constituye uno de los retos más desafiantes que la humanidad debe abordar durante los próximos años. Con la actual tasa de crecimiento de la población mundial (se espera que para 2050 se haya duplique 
su valor en 2000 (Schiffer, 2008)), en combinación con la rápida expansión de la industrialización global, la demanda de energía crece a un ritmo vertiginoso (Dincer, 2000), estimándose un crecimiento de al menos un orden de magnitud para 2050 (Schiffer, 2008) sin previsiones de ser satisfecho (Figura 1). En este escenario, otros problemas no menos importantes, como el calentamiento global, la creciente polución de la atmósfera, las emisiones de ozono y la deforestación juegan un papel condicionante, resultando en un complejo escenario que debe ser abordado para garantizar la viabilidad del futuro de la humanidad.

\section{FIGURA I. Población sin acceso a electricidad}

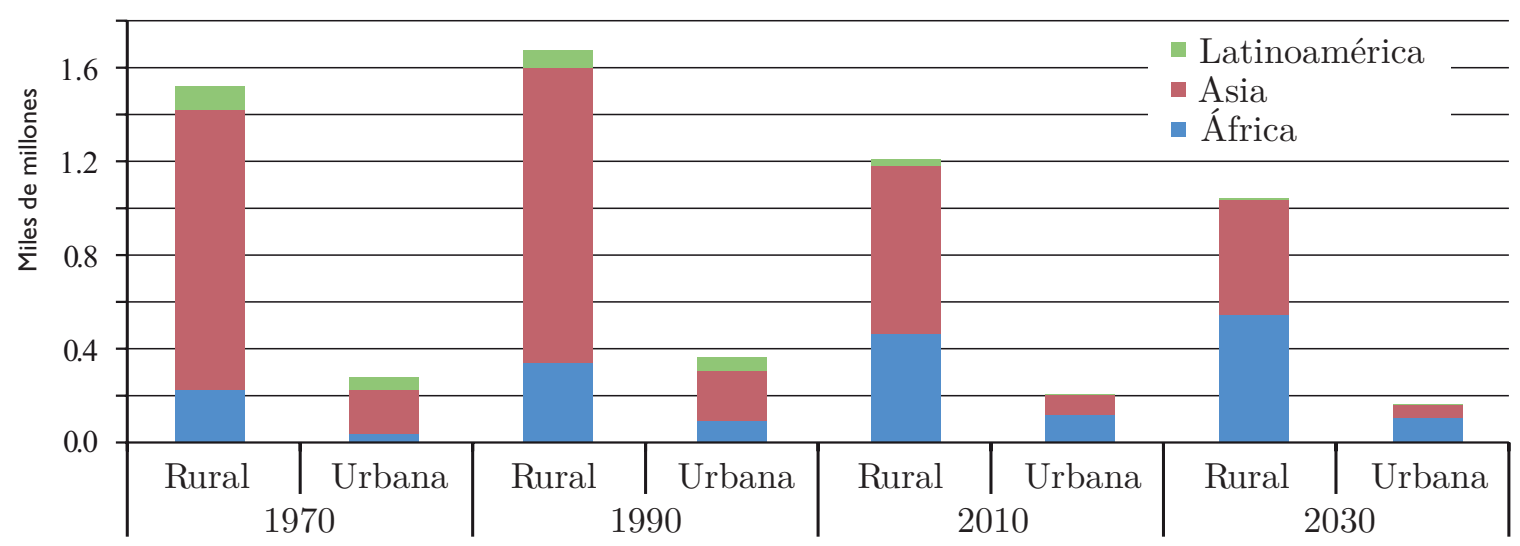

Fuente: (Bhattacharyya, 2012).

Durante el periodo 2000-2015 los Objetivos de Desarrollo Sostenible (ODS) de las Naciones Unidas (Sachs et al., 2005) han logrado colocar en el foco de atención este debate gracias al séptimo de sus diecisiete objetivos, que persigue garantizar el acceso a una energía asequible, segura, sostenible y moderna para todos. Así, el problema del acceso universal a la energía ha adquirido una especial relevancia, siendo un factor común en la mayoría de agendas políticas de los últimos años. Además, este objetivo evidencia la importancia de universalizar el acceso a energía sostenible para los países en desarrollo, lo cual es fundamental para garantizar su desarrollo social y económico (Chien, Taichen and Hu, Jin-Li, 2008). Prueba de esto es que cada vez es más habitual la inclusión de programas de electrificación rural en países en desarrollo en la región de América Latina y el Caribe (LAC) (Pereira et al., 2011). En este caso en particular, es interesante destacar que, si bien la contribución de esta región a las emisiones globales de $\mathrm{CO}_{2}$ es baja, extender el acceso a la energía para combatir la pobreza energética de esta región constituye un reto especialmente difícil. 


\section{I.I. La pobreza energética en Honduras}

Honduras constituye uno de los países más castigados por la pobreza energética en Latinoamérica. El Programa de las Naciones Unidas para el Desarrollo (PNUD) sitúa a Honduras en el puesto 133 según su índice de Desarrollo Humano (IDH) (UNDP, 2018). Con un Producto Interior Bruto (PIB) de 22.98 billones de dólares en 2017 (World Bank, 2018) se sitúa en el puesto 29 de los 42 países que componen LAC. La matriz energética de Honduras está formada casi exclusivamente por el consumo de combustibles fósiles y biomasa, que representan el $87.5 \%$ del origen de la energía consumida en el hogar.

Es de destacar la especial situación de vulnerabilidad de la población rural, con uno de los ratios de electrificación mas bajos de toda Latinoamérica (González-Eguino, 2015). La principal barrera para el acceso a la red eléctrica de esta parte de la población radica en el modelo de distribución centralizada, que castiga fuertemente a las comunidades aisladas y con dificultades de acceso, que no sólo se traducen en la imposibilidad de acceder a la red eléctrica, sino también a otros servicios básicos como sistemas de comunicación o incluso agua potable. Por este motivo, estas comunidades quedan relegadas al uso de fuentes de energía tradicionales, resultando en un consumo anual aproximado de 7.5 millones de metros cúbicos de madera (Flores et al., 2011).

Aunque los bosques son un recurso natural abundante en Honduras, los incendios y la explotación maderera generan tasas de deforestación de hasta 67.000 hectáreas anuales. Por supuesto, a esto se añaden problemáticas inherentes al uso de madera y combustibles fósiles en el hogar, tales como el desarrollo de problemas de salud, especialmente en niños (Maes and Verbist, 2012; Gordon et al., 2014).

\section{I.2. La energía renovable como elemento clave}

A la vista de la problemática energética de Honduras, unida a la riqueza de sus recursos naturales (Department of Physics, Autonomous National University of Honduras, 2008), apostar por las energías renovables como herramienta clave para combatir la pobreza energética, contribuyendo a construir un futuro más sostenible se hace imperativo. No son pocos los casos de éxito que han demostrado la adecuabilidad de estas soluciones para resolver el problema energético de zonas aisladas (Zelaya, 2009; Kusakana, 2015), habiéndose convertido el estudio de los efectos de la electrificación en un área de especial interés en la comunidad científica (Haidar et al., 2012; Wijayatunga and Attalage, 2003; Akinyele and Rayudu, 
2016). En líneas generales, el impacto de los proyectos de electrificación (Cook, $2011)$ puede resumirse en tres áreas: impacto económico, social y medioambiental:

- En primer lugar, el acceso a la electrifidad diversifica fuertemente el desarrollo de actividades económicas (Haidar et al., 2012), y permite la preservación de los alimentos destinados al comercio. Adicionalmente, se promueve el emprendimiento y la creación de nuevas ideas de negocio y actividades generadoras de ingresos, no sólo en aquellas áreas relacionadas directamente con las nuevas tecnologías disponibles, como el entretenimiento o las comunicaciones, sino también actividades tradicionales como la venta de bebidas o hielo.

- En segundo lugar, el incremento de la actividad económica y el emprendimiento se traduce en el incremento de ingresos de las familias. Acceder a la electricidad también mejora las condiciones de los colegios y escuelas, promoviendo un mejor desarrollo de las actividades educativas. Además, las familias reducen los recursos económicos destinados al combustible para cocinar y para la iluminación (Wijayatunga and Attalage, 2003), que es sustituido por tarifas eléctricas generalmente más económicas.

- Por último, hay una relación muy clara entre el uso de energías renovables y la preservación del medio ambiente (Akinyele and Rayudu, 2016; Ismail et al., 2013). No sólo estos sistemas minimizan el impacto ambiental, sino que su uso promueve la preservación del entorno, estimulando en los beneficiarios el interés por proteger y cuidar el medio ambiente.

Por este motivo, la utilización de sistemas de energía renovables puede ser la clave para revolver el problema energético de Honduras, especialmente gracias a su riqueza en recursos naturales. Por supuesto, este enorme potencial energético no es un gran desconocido en el país: desde 2003, la Fundación Hondureña de Investigación Agrícola (FHIA) ha venido desarrollando proyectos de electrificación rural basados en el uso de fuentes de energía renovable. En particular, con el programa Eco-Sistemas de FHIA, se persigue impulsar la instalación de pequeñas y económicas plantas hidroeléctricas para abastecer eléctricamente a las pequeñas comunidades remotas de las zonas más castigadas por la pobreza energética.

\section{I.3. El programa Eco-Sistemas de FHIA}

La iniciativa de utilizar sistemas micro-hidráulicos en las comunidades rurales de Honduras nace en 2003 por iniciativa del Roberto Fromm, ingeniero de FHIA, con 
el diseño e instalación de una micro-turbina hidráulica en la aldea de El Triunfo, en el Departamento de Colón. Motivado por el interés de las comunidades cercanas en el sistema nació el programa Eco-Sistemas, con el propósito de replicar esta estrategia en diferentes emplazamientos. El desarrollo de cada uno de los proyectos hidroeléctricos de este programa puede organizarse en las siguientes fases:

- Selección de la micro-cuenca y evaluación del sitio

- Aceptación de la comunidad

- Preparación de equipo e instalación del sistema

- Capacitación

\section{I.3.I. Selección de la micro-cuenca y evaluación del sitio}

La comunidad beneficiaria del proyecto se debe identificar en base a su potencial natural (recurso hídrico suficiente, zona boscosa no intervenida, etc). Una vez identificado un posible emplazamiento se hace una estimación del potencial hidroeléctrico mediante mediciones de caudal de agua y altura geográfica aprovechable.

\section{I.3.2. Aceptación de la comunidad}

Una vez abordados los aspectos técnicos del proyecto, tiene lugar una asamblea con los miembros de la comunidad, donde se les pone en conocimiento de la capacidad del sistema, así como las necesidades durante la instalación y su posterior mantenimiento. De esta manera se promueve un compromiso por parte de los beneficiarios.

\section{I.3.3. Instalación del sistema}

Una vez se cuenta con la aceptación de la comunidad, los técnicos de FHIA deciden el emplazamiento de los diferentes elementos que conforman el sistema, fundamentalmente en base a su experiencia y a estimaciones insitu, tras lo cual se procede a la instalación del mismo. Una parte esencial de estos proyectos radica en la participación de la comunidad en las diferentes labores de obra civil e instalación, que es asumida como contra-parte. Así, la comunidad es responsable de elaborar un plan de trabajo y de desarrollar las labores necesarias bajo la coordinación del personal técnico de FHIA. 


\section{I.3.4. Capacitación}

Por último, con el fin de evitar posteriores problemas derivados del mantenimiento del sistema, FHIA organiza una sesión de capacitación con la comunidad, donde se designan a las personas responsables del correcto manejo y mantenimiento de la planta. Esto implica además la elaboración de un plan preventivo y de respuesta ante posibles averías, así como un sistema de retribución que permita sufragar los posibles gastos derivados de las mismas.

\section{I.4. Objetivos del trabajo}

Durante la primera parte de la investigación, se realizó una visita a FHIA, donde se estudió en detalle el procedimiento desarrollado para los proyectos del programa Eco-Sistemas, y se visitó una de las comunidades intervenidas para identificar posibles líneas de mejora. En base a ésto, se propuso una línea de mejora principal basada en optimizar el diseño de las plantas microhidráulicas, de manera que el aprovechamiento de los recursos naturales se determine de forma óptima. A ésta propuesta se incorporaron posteriormente dos mejoras menores, relativas al equipamiento utilizado en la fabricación de la turbina y al sistema eléctrico de monitorización.

\section{Descripción de los sistemas micro-hidráulicos}

En este apartado se introduce brevemente la energía hidroeléctrica, así como los sistemas de micro-generación hidroeléctrica desarrollados e instalados por FHIA en los proyectos del programa Eco.Sistemas.

\section{I. Energía hidroeléctrica}

La energía hidroeléctrica se define como aquella energía obtenida a partir del potencial de una fuente de agua. Las centrales hidroeléctricas (Figura 2 consisten en extraer parte del flujo de agua de un cauce natural mediante una pequeña barrera denominada presa (Figura 3-izqda.), y conducirla posteriormente aguas abajo mediante una conducción denominada tubería forzada, a lo largo de la cual su energía potencial se transforma en presión. La tubería forzada desemboca en un pequeño edificio denominado casa de máquinas (Figura 3-dcha.), donde 
se instala una turbina y un generador. Al final de la tubería forzada, el agua es inyectada en la turbina, donde la presión del agua mueve unos álabes y se transforma en energía mecánica.

Esta última es convertida a su vez en energía eléctrica en el generador. Es importante destacar que, después de este proceso, el agua es devuelta a su cauce original, por lo que el impacto ambiental es prácticamente nulo.

\section{FIGURA 2. Esquema de una planta hidroeléctrica}

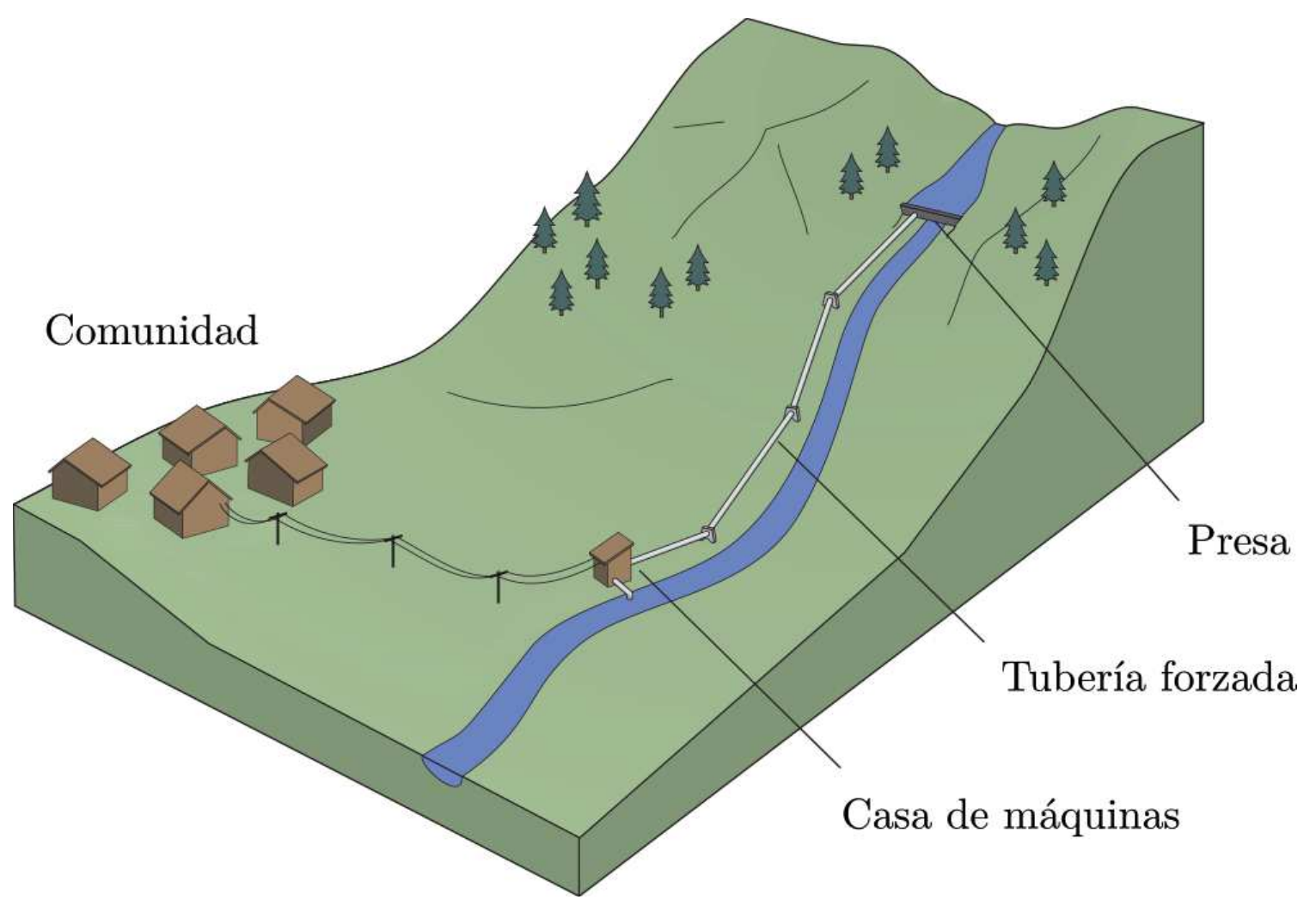


FIGURA 3. Fotografías de la presa (izquierda) y casa de máquinas (derecha) instalados por FHIA

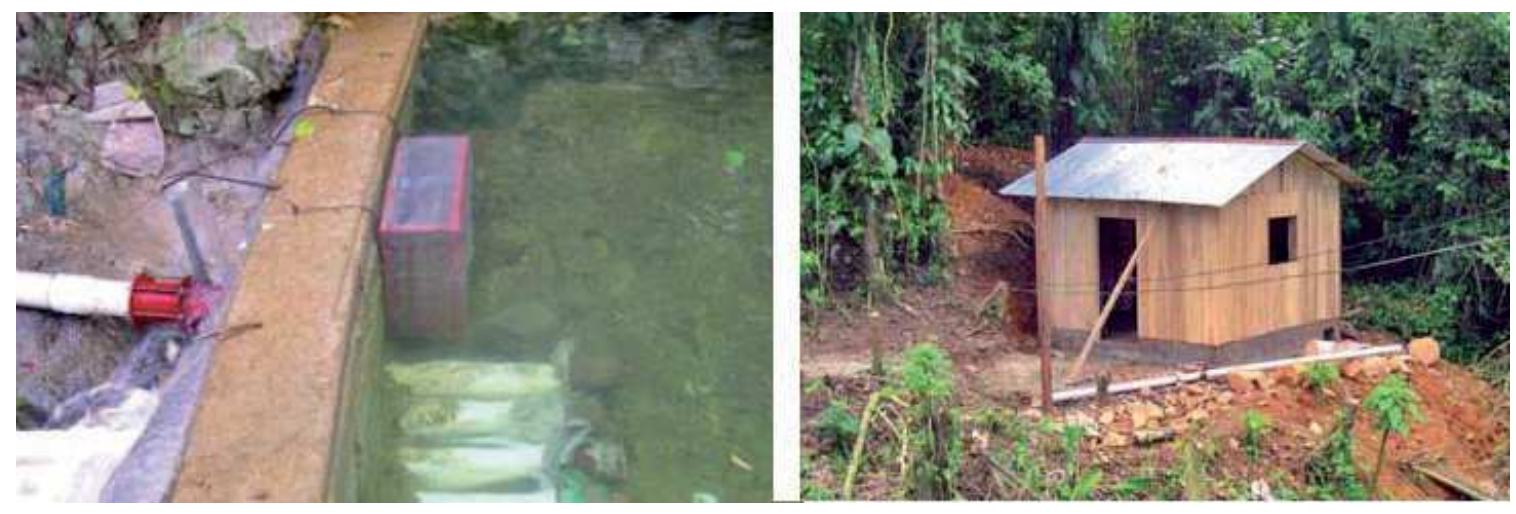

FIGURA 4. Turbina y generador desarrollados e instalados por FHIA

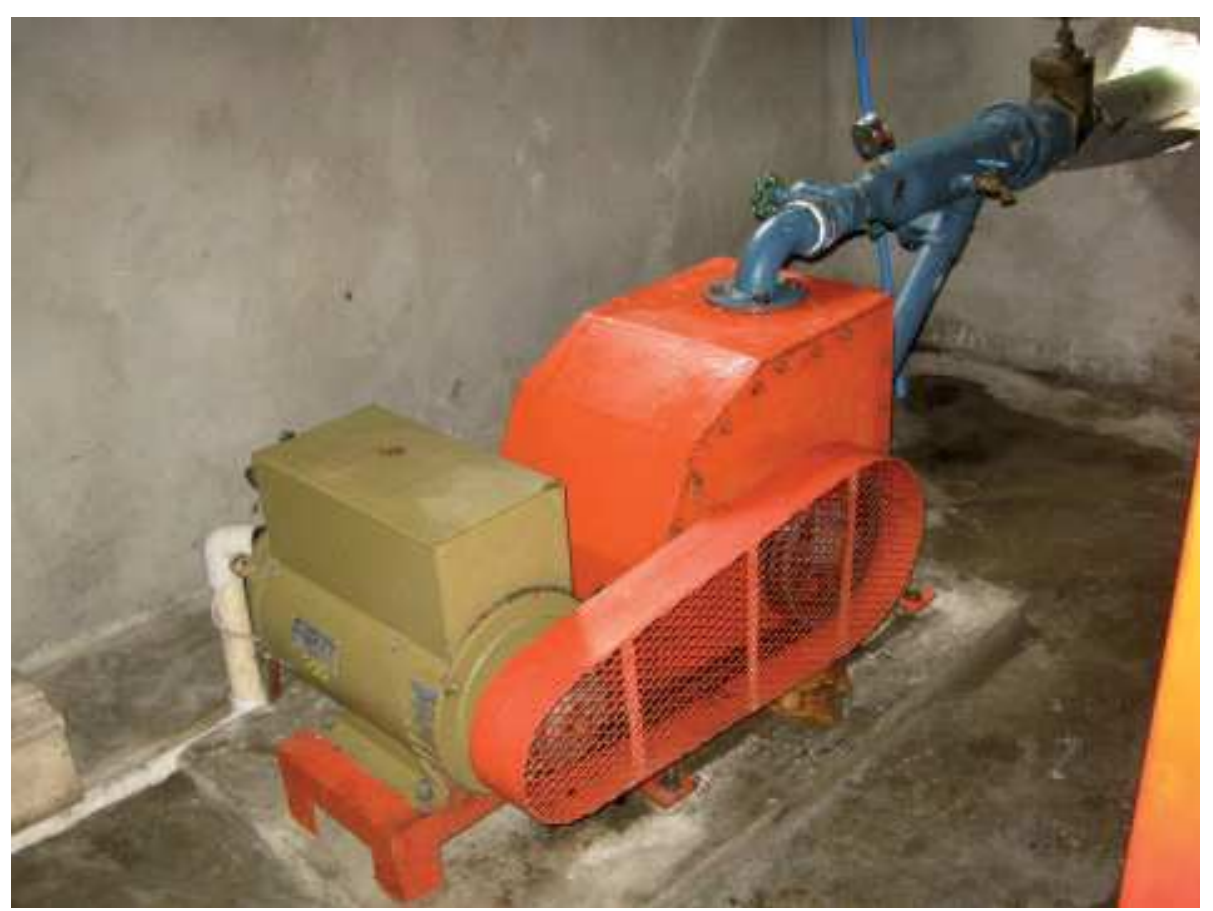

\subsection{Micro-plantas hidráulicas instaladas por FHIA}

El concepto micro-generación hace referencia a niveles de generación del orden de los $10 \mathrm{~kW}$. Este tipo de instalaciones tiene la ventaja de poder prescindir de ciertos elementos necesarios en grandes centrales hidroeléctricas (como requerir 
grandes caudales, almacenamiento de agua o sistemas de control), brindando la oportunidad de instalar sistemas eficientes con una inversión baja. Por este motivo, y dados los bajos niveles de demanda eléctrica de las comunidades rurales intervenidas, FHIA desarrolla sistemas de microgeneración (Figura 4) para abastecer las comunidades. Las turbinas Pelton son un tipo de turbina especialmente eficiente con caudales pequeños, compuesta por una serie de cucharas dispuestas circunferencialmente, sobre las que impacta un chorro de agua (Figura 5).

\section{FIGURA 5. Esquema de funcionamiento de una turbina de tipo Pelton}

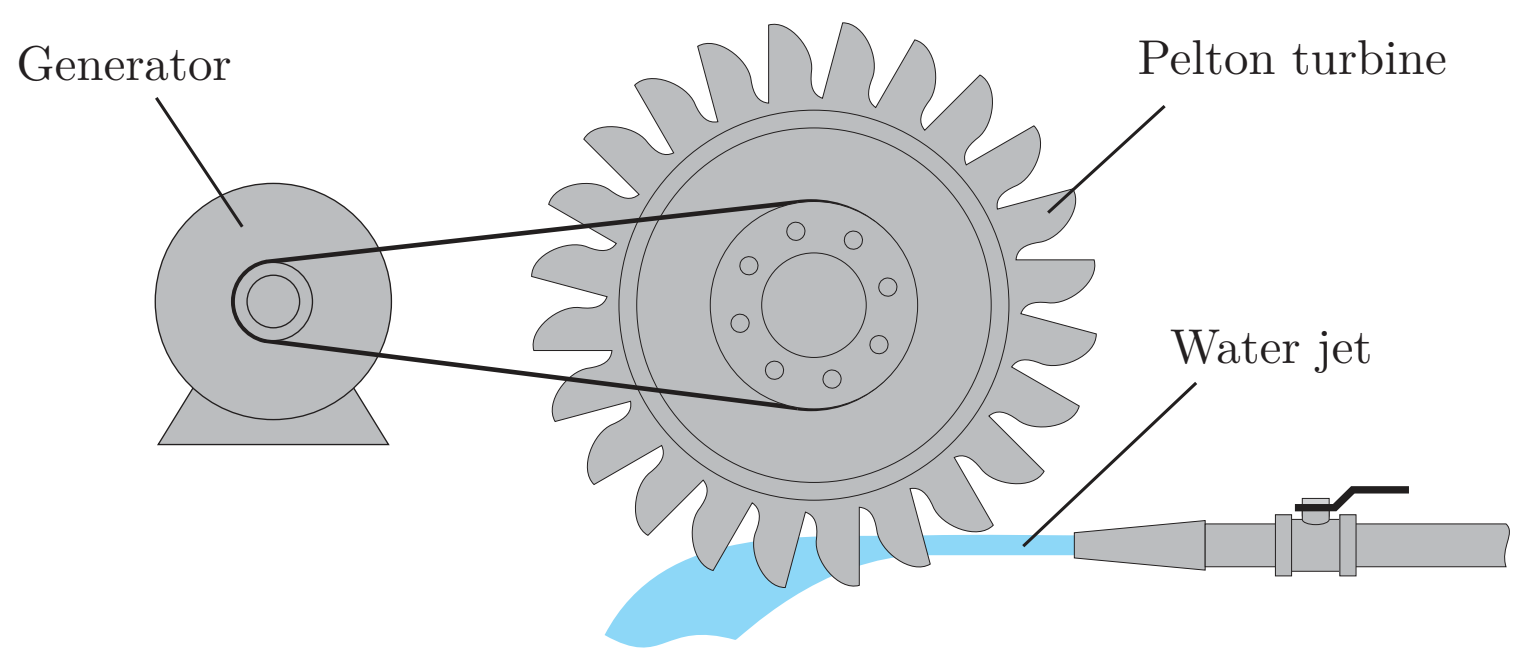

La decisión más importante en el proceso de diseño de la planta microhidroeléctrica es la elección del emplazamiento de la presa (punto de obtención del agua) y de la casa de máquinas (punto de turbinado del agua). Posteriormente se decide el trazado de la tubería forzada, que está compuesta por una serie de segmentos rectos de tubería. La decisión del emplazamiento de los dos primeros elementos se realiza a priori, fundamentalmente en base a la experiencia de los propios técnicos. Sin embargo, la distribución y disposición de los diferentes segmentos que conforman la tubería forzada se decide sobre la marcha (ver Figura 6), y se deja en manos de las personas que desarrollan la obra civil. 
FIGURA 6. Instalación de la tubería forzada

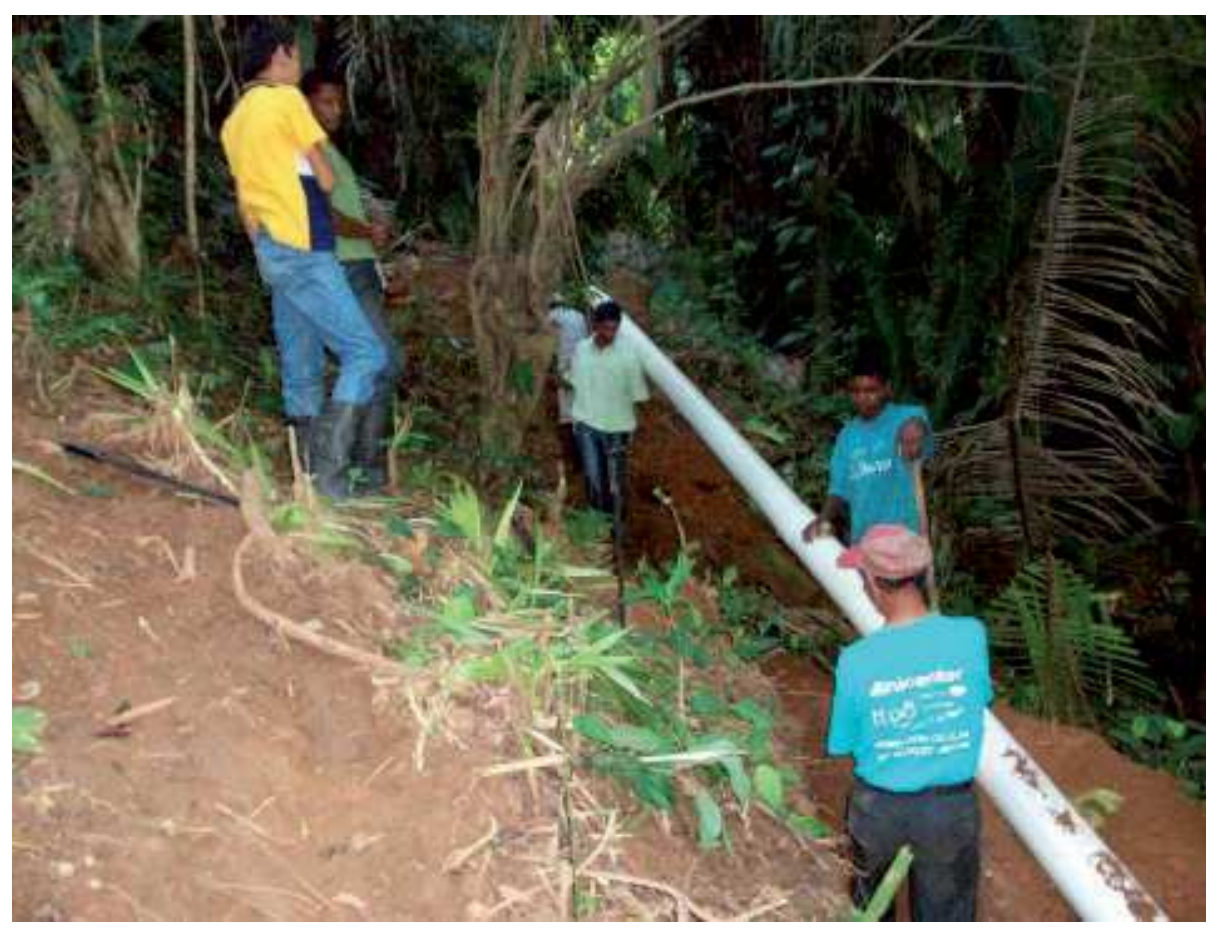

En líneas generales, la distancia neta vertical entre los puntos de obtención y turbinado del agua se traduce en la máxima energía potencial disponible de la planta, y la longitud total de la tubería se traduce en una determinada pérdida hidráulica como consecuencia de la fricción interna del agua contra las paredes de la misma. Por este motivo, estas decisiones condicionan la capacidad y rendimiento de la planta. Fundamentalmente, los técnicos tratan de conseguir una altura suficiente para generar la potencia deseada pero manteniendo la tubería forzada tan corta como sea posible. Una dificultad añadida es la necesidad de instalar soportes para salvar las diferencias entre el terreno y la tubería forzada a lo largo del terreno, como se puede ver en la fotografía de la Figura 7. 
FIGURA 7. Instalación de soportes para salvar la distancia entre la tubería forzada y las irregularidades del terreno

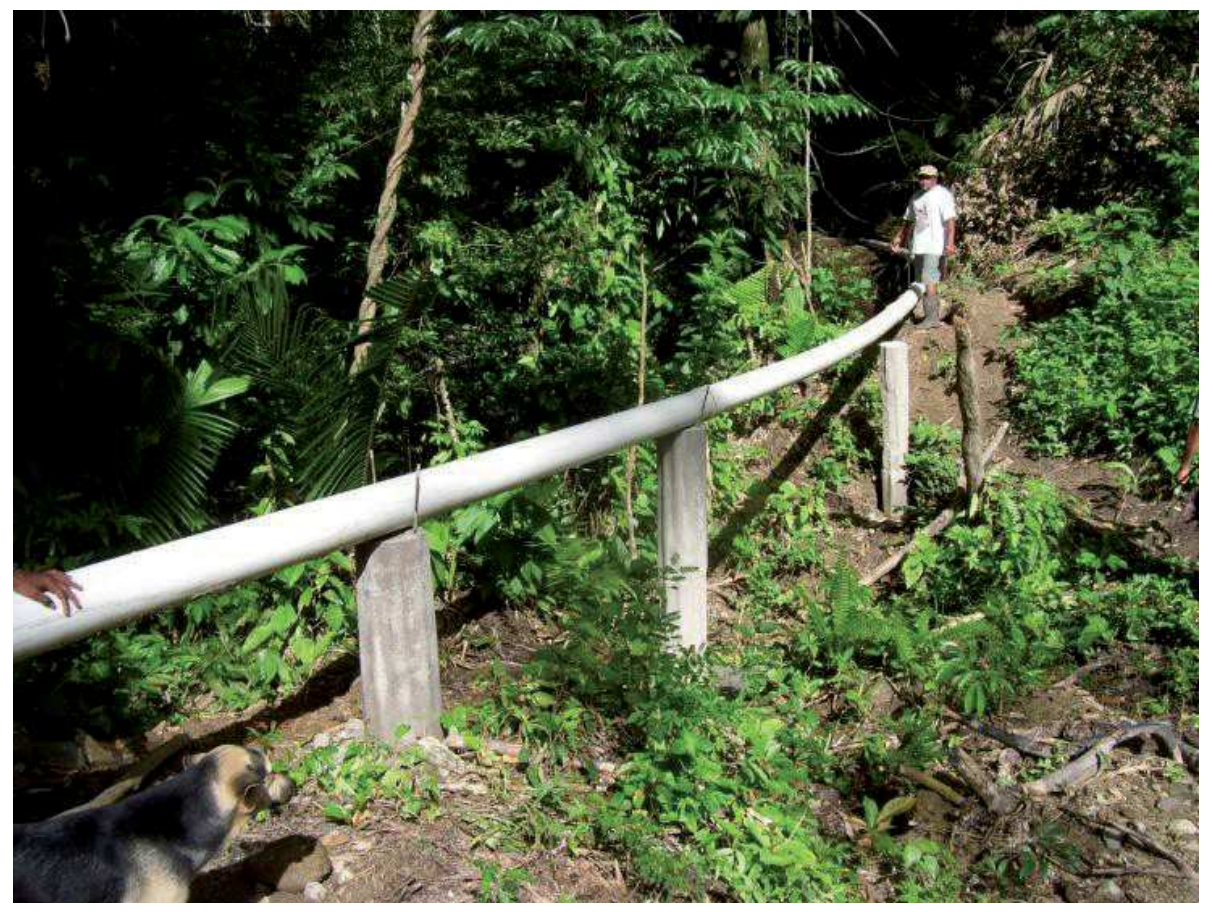

\section{Estrategias de optimización para asistir el diseño de la planta}

La innovación principal consiste en diseñar e implementar una estrategia de optimización numérica para el diseño de las plantas, de manera que las decisiones anteriormente descritas relativas al emplazamiento de la casa de máquinas y de la presa, así como el trazado y disposición de los segmentos de la tubería forzada se haga de forma automática y atendiendo a la combinación más óptima.

\section{I. Modelado del sistema y formulación del problema}

En primer lugar se desarrolla un modelo matemático capaz de reproducir el comportamiento de la planta hidroeléctrica. Este modelo se propone como herramienta para determinar el rendimiento y la capacidad de la planta diseñada en función de las sus diferentes elementos y su disposición, considerando las características geográficas naturales del terreno. 
El modelo, explicado en profundidad en (Tapia et al., 2018), se puede resumir en las siguientes expresiones para la potencia generada, $P$, el caudal turbinado, $Q$, y el coste de la planta, $C$ :

$$
\begin{aligned}
P & =\frac{\eta \rho}{2 S_{n o z}^{2}}\left[\frac{H_{g}}{\frac{1}{2 g S_{n o z}^{2}}+k_{p} \frac{L_{p}}{D_{p}^{5}}}\right]^{\frac{3}{2}} \\
Q & =\left[\frac{H_{g}}{\frac{1}{2 g S_{n o z}^{2}}+k_{p} \frac{L_{p}}{D_{p}^{5}}}\right]^{\frac{1}{2}} \\
C & =k_{p} D_{p}^{2}\left(L_{p}+\lambda_{c} n_{c}\right),
\end{aligned}
$$

donde $\mathrm{Hg}$ y $L P$ representan, respectivamente, la distancia neta vertical entre presa y turbina y la longitud de la tubería forzada, tal y como se describieron anteriormente. Para evaluar estas dos variables, se propuso considerar el perfil del río como una curva en el espacio $x y z$. El problema es estudiado en dos dimensiones mediante su desarrollo plano, como se muestra en la Figura 8.

\section{FIGURA 8. Desarrollo bidimensional del perfil espacial del río}

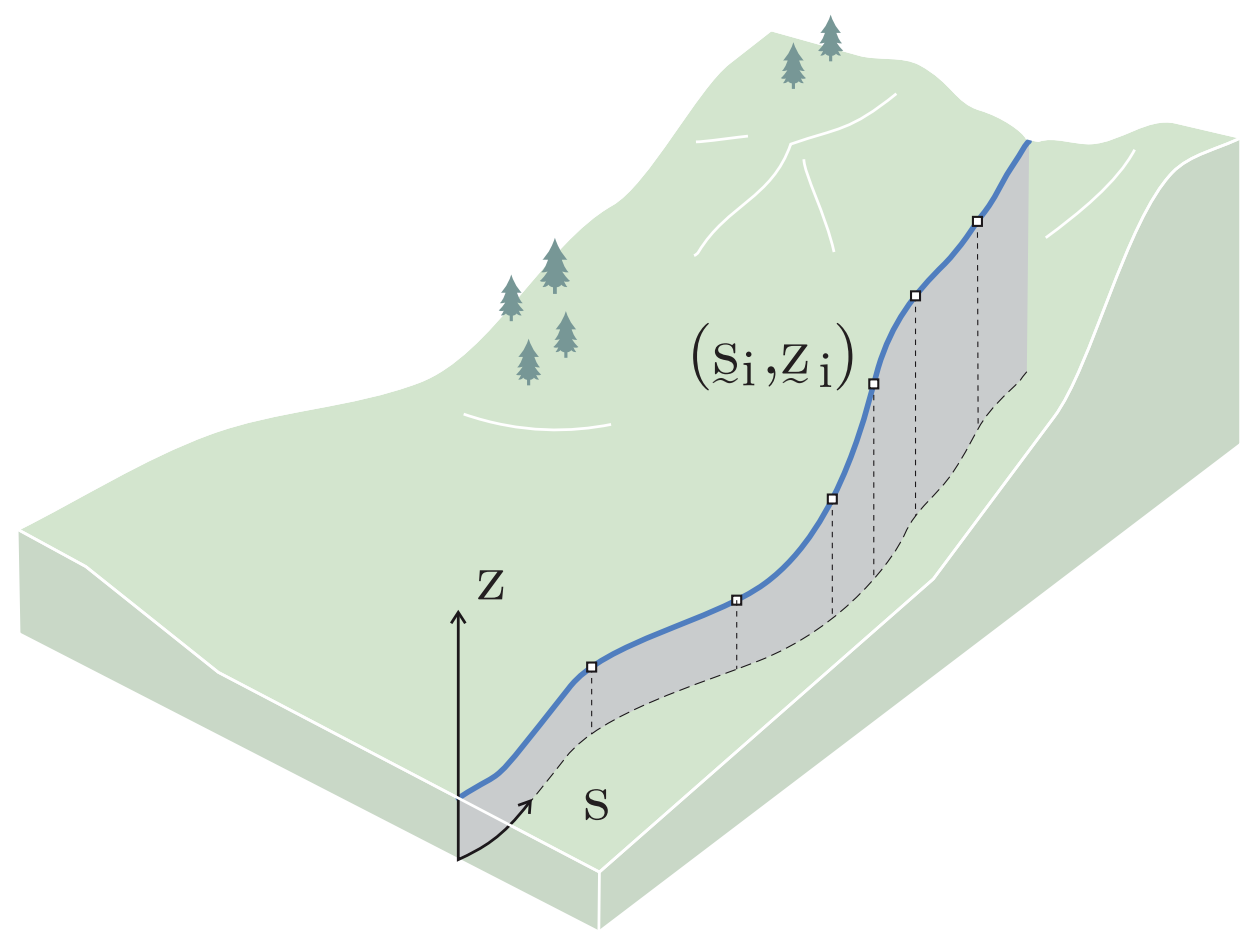


En base a esta geometría, se propone definir la tubería forzada como una quebrada que interpola una serie de puntos, denominados nodos, del perfil del río. De esta manera, el primero y el último de estos nodos representan, respectivamente, el emplazamiento de la casa de máquinas y la presa. El resto de ellos representan conexiones entre dos segmentos consecutivos de la tubería forzada. Esto permite además determinar la longitud de línea eléctrica necesaria, en caso de que ésta sea trazada siguiendo el perfil del río, lo cual suele ser habitual cuando el terreno presenta dificultades de acceso.

En base a esta geometría se propone determinar la ubicación de los diferentes elementos (nodos) que permitan a la instalación resultante satisfacer una determinada potencia para abastecer la comunidad con el mínimo coste posible, atendiendo a una restricción adicional relativa a la cantidad de agua extráıda del río y limitando las dimensiones de las excavaciones y soportes necesarios, estimados en función de la naturaleza del suelo. Así, se propone el siguiente problema de optimización:

\begin{tabular}{|c|c|c|c|}
\hline \multirow{4}{*}{$\begin{array}{r}\text { Minimizar } \\
\text { Sujeto a }\end{array}$} & Coste Potencia & $\geq$ & Potencia mínima de abastecimiento \\
\hline & Caudal & $\leq$ & Caudal máximo extráıble \\
\hline & Soportes & $\leq$ & Máxima altura de soporte instalable \\
\hline & Excavaciones & $\leq$ & Máxima excavación admisible \\
\hline
\end{tabular}

Además, para evitar las complicaciones derivadas de instalar una tubería forzada con un excesivo número de segmentos y de conexiones entre ellos, se considera un coste (en forma de longitud equivalente de tubería) de los mismos en la función de coste global. Para abordar el problema propuesto se propone en primer lugar una eficiente estrategia basada en programación entera. A continuación se propone mejorar algunos inconvenientes de este enfoque mediante el desarrollo de estrategias de optimización meta-heurísticas basadas en algoritmos evolutivos.

\subsection{Optimización mediante programación entera}

La primera propuesta para abordar el problema de optimización se basa en partir de una discretización del perfil del río a partir de un conjunto de $N$ puntos, obtenibles mediante un estudio topográfico in-situ o mediante mapas de curvas de nivel. Cada uno de estos $N$ puntos (si,zi) se considera como un emplazamiento potencial de un nodo. A partir de esta discretización se propone un conjunto de $N$ 
variables discretas $\delta$, definidas de tal forma que se coloca un nodo en el punto i si y sólo si $\delta i=1$. Así, cada posible solución vendrá definida por una combinación de las $N$ variables binarias $\delta$, tal y como se esquematiza en la Figura 9.

\section{FIGURA 9. Ejemplo de una posible solución del problema}

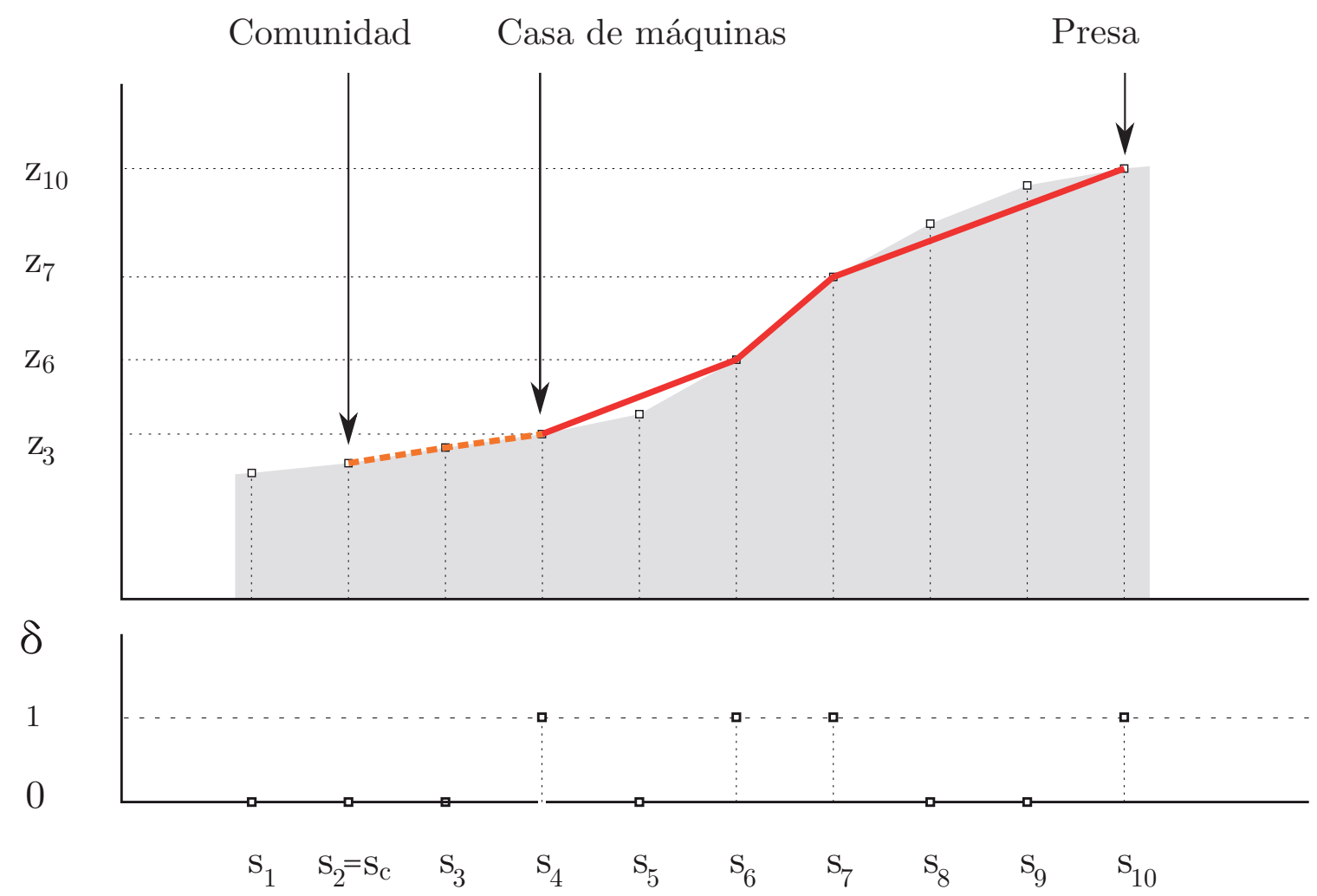

Definiendo adicionalmente un conjunto de $N(N-1)$ variables $\gamma$ ii de tal forma que:

$$
\gamma i i=1 \leftrightarrow \delta i=\delta j=1,
$$

y utilizando una estrategia explicada en detalle en (Tapia et al., 2018) se transforma el problema en una formulación entera lineal, de forma que puede expresarse en la forma: 


$$
\begin{array}{ll}
\min & \sum_{j=1}^{n} c_{j} x_{j}, \\
\text { s.t. } & \sum_{j=1}^{n} a_{i j} x_{j}=b_{i} \quad i \leq 1 \ldots m, \\
& \sum_{j=1}^{n} a_{e q, i j} x_{j}=b_{e q, i} \quad i=1 \ldots m_{e q}, \\
& x_{j} \in \mathbb{Z}
\end{array}
$$

Con el problema así descrito, se realiza su implementación numérica en MATLAB para ser resuelto mediante un algoritmo de ramificación y poda. Estas estrategias se basan en dividir el espacio de búsqueda en una estructura de árbol (ramificación), de manera que puedan ser exploradas y acotadas, pudiendo ser eliminadas (podadas) prematuramente si no pueden conducir a soluciones óptimas. Estos algoritmos son especialmente eficientes resolviendo problemas con formulación entera, por lo que resulta apropiado para el problema en cuestión.

Para verificar la capacidad del algoritmo propuesto de resolver el problema de optimización estudiado, se define un perfil de un río aleatorio (representado en la Figura 10), en base al cual se propone el diseño de una planta micro-hidroeléctrica análoga a las instaladas por FHIA. Se definen además diferentes casos de estudio para comprobar la validez de las diferentes partes del algoritmo (listados en al Tabla 3.2.

\section{TABLA I. Casos propuestos para el problema de ejemplo}

\begin{tabular}{|l|l|c|c|c|c|c|c|}
\multicolumn{2}{l|}{ Caso } & Fun. obj. & $\begin{array}{c}P_{\min } \\
(\mathrm{kW})\end{array}$ & $\lambda_{c}(\mathrm{~m})$ & $\begin{array}{c}\epsilon_{\text {sup }} \\
(\mathrm{m})\end{array}$ & $\begin{array}{c}\epsilon_{\text {exc }} \\
(\mathrm{m})\end{array}$ & $\begin{array}{c}D_{p} \\
(\mathrm{~cm})\end{array}$ \\
\hline 1 & Referencia & $\min C$ & 8.0 & 50 & 1.5 & 1.5 & 20 \\
\hline 2 & Sin coste de nodos & $\min C$ & 8.0 & 0 & 1.5 & 1.5 & 20 \\
\hline 3 & Terreno resistente & $\min C$ & 8.0 & 50 & 3.0 & 0.5 & 20 \\
\hline 4 & Sin adaptabilidad & $\min C$ & 8.0 & 50 & 1 & 1 & 20 \\
\hline 5 & Mayor demanda & $\min C$ & 20.0 & 50 & 1.5 & 1.5 & 20 \\
\hline
\end{tabular}


FIGURA I0. Perfil de río de ejemplo

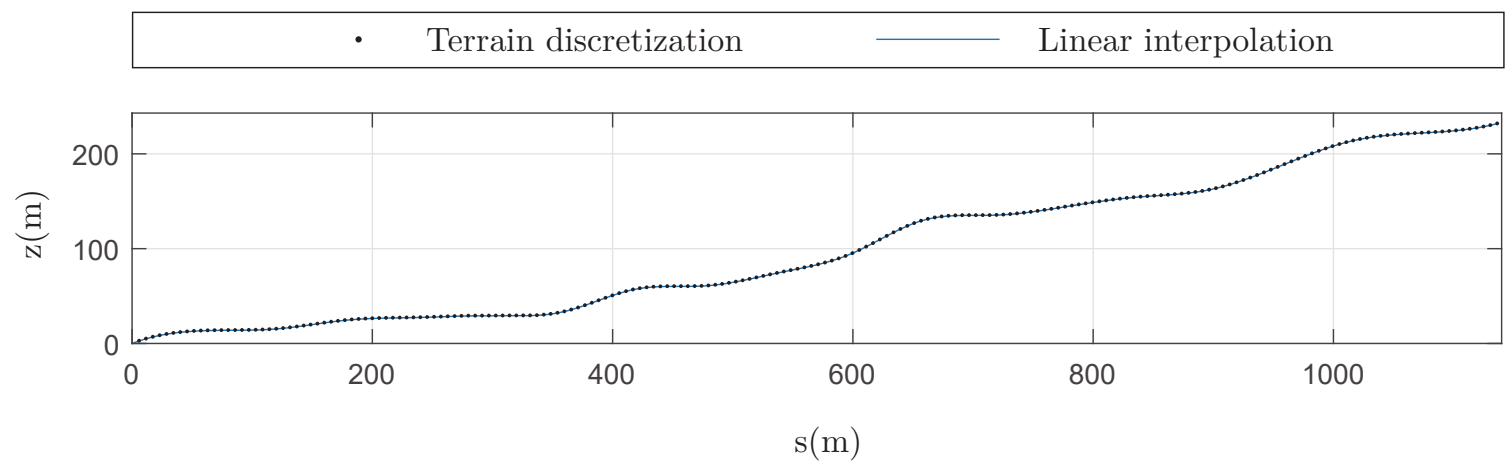

Las soluciones obtenidas para los casos presentados se enumeran en la Tabla 3.2. Asimismo, se muestran en la Figura 11 los trazados correspondientes a tales soluciones.

\section{TABLA 2. Resultados obtenidos para el problema de ejemplo utilizando el algoritmo propuesto de programación entera}

\begin{tabular}{|c|c|c|c|c|c|c|c|c|c|c|}
\hline \multicolumn{3}{|c|}{ Descripción del problema } & \multicolumn{7}{|c|}{ Solución } \\
\hline & $\begin{array}{c}P_{\min } \\
(\mathrm{kW})\end{array}$ & $\begin{array}{c}\lambda_{c} \\
(\mathrm{~m})\end{array}$ & $\begin{array}{c}\epsilon_{\text {sup }} \\
(\mathrm{m})\end{array}$ & $\begin{array}{c}\epsilon_{\text {exc }}(\mathrm{m}) \\
(\mathrm{kW})\end{array}$ & $\begin{array}{c}P \\
(\mathrm{Hg})\end{array}$ & $\begin{array}{c}L_{p} \\
(\mathrm{~m})\end{array}$ & $\begin{array}{c}Q \\
(\mathrm{~L} / \mathrm{s})\end{array}$ & $n_{c}$ & $\begin{array}{c}C \\
(\mathrm{k} \$)\end{array}$ \\
\hline 1 & 8 & 50 & 1.5 & 1.5 & 8.050 & 69.124 & 186.601 & 13.980 & 4 & 10.825 \\
\hline 2 & 8 & 0 & 1.5 & 1.5 & 8.050 & 69.124 & 186.602 & 13.980 & 5 & 5.225 \\
\hline 3 & 8 & 50 & 3.0 & 0.5 & 8.025 & 68.981 & 186.594 & 13.966 & 4 & 10.825 \\
\hline 4 & 8 & 50 & $\infty$ & $\infty$ & 8.025 & 68.981 & 185.186 & 13.966 & 2 & 7.985 \\
\hline 5 & 20 & 50 & 1.5 & 1.5 & 20.179 & 127.657 & 460.088 & 18.976 & 8 & 24.082 \\
\hline
\end{tabular}

A la vista de los resultados de los diferentes casos se pueden hacer varios comentarios:

- Para el primer caso se observa que el algoritmo es capaz de determinar el trazado óptimo de la planta, de manera que la planta resultante es capaz de generar los $8 \mathrm{~kW}$ de potencia exigidos sin sobrepasar el límite de caudal impuesto y adaptándose correctamente al terreno.

- En el segundo caso, en el que no se han considerado los costes equivalentes de los nodos, se puede observar cómo la solución obtenida por el algoritmo es similar a la anterior pero incluye un número mayor de nodos (5 en lugar de 4). 
FIGURA II. Soluciones obtenidas para el problema de ejemplo utilizando programación entera
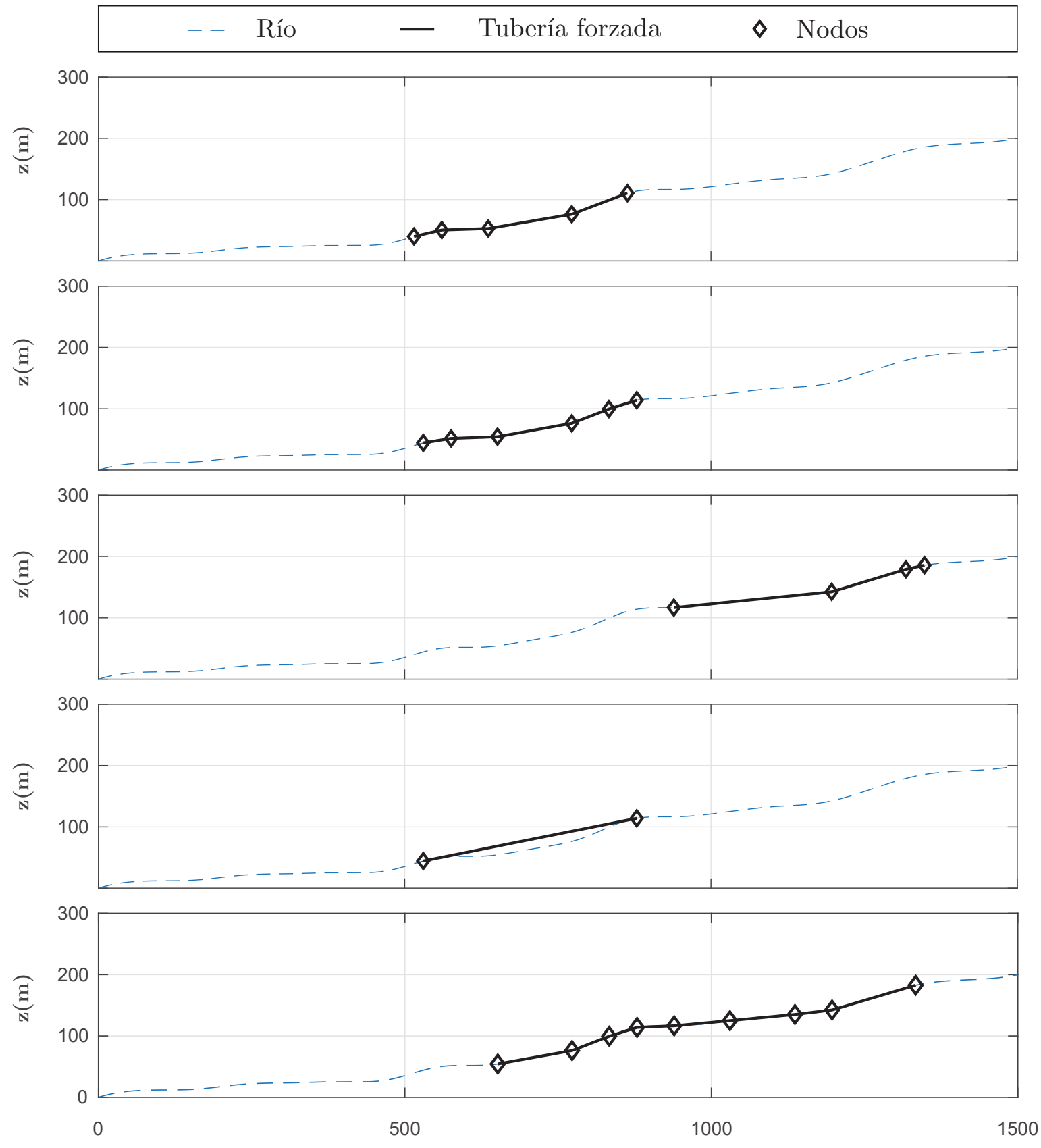

$\mathrm{s}(\mathrm{m})$ 
- En el tercer caso, la altura permitida de los soportes y al reducir la profundidad de las excavaciones se estimula la inclusión de soportes en lugar de excavaciones, y se observa el algoritmo tiende a mover la solución óptima hacia una zona cóncava del perfil.

- En el cuarto caso, como era de esperar, la solución óptima consiste en un trazado con un único segmento de tubería, puesto que se han eliminado del problema las restricciones asociadas a la adaptabilidad del perfil de la tubería forzada al terreno.

- Por último, se puede observar en el quinto caso cómo al incrementar la potencia demandada el algoritmo resulta en soluciones con una mayor altura bruta y una mayor longitud.

Además, echando un vistazo a los tiempos de computación (representados en la Figura 12) se puede comprobar que el algoritmo es capaz de obtener una solución en tiempos razonablemente bajos (del orden del minuto) para valores de discretización suficientemente altos.

\section{FIGURA 12. Coste computacional y valor de la función objetivo para diferentes niveles de discretización}

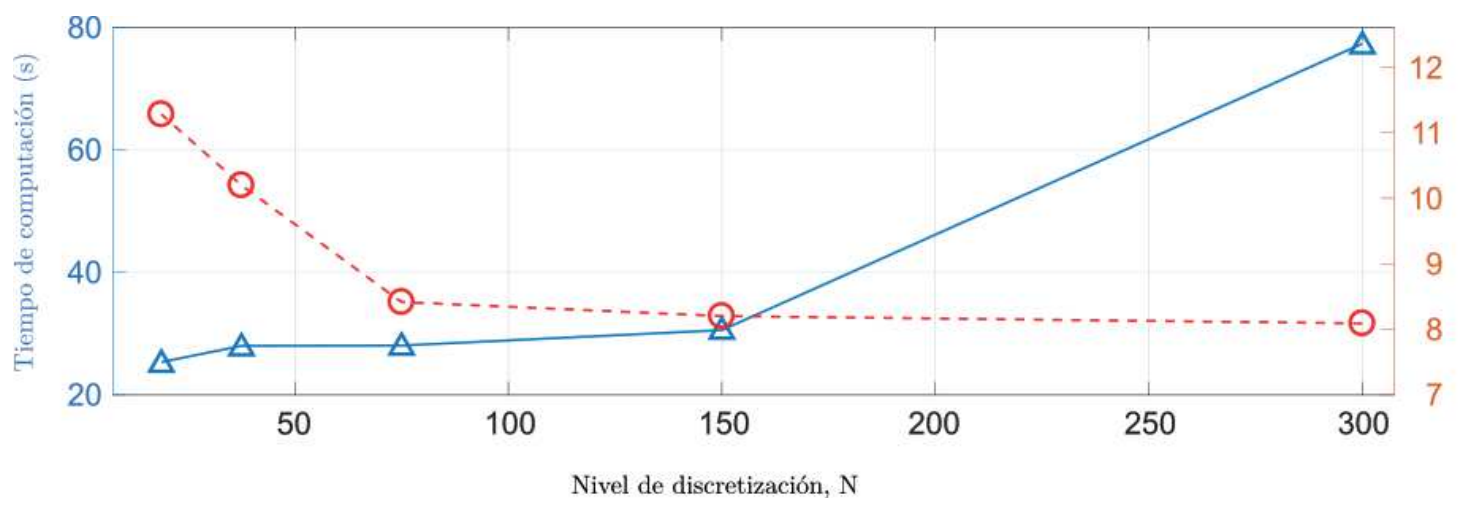

Como conclusión general se puede extraer que el algoritmo propuesto constituye una buena herramienta para asistir el diseño de las plantas microhidroeléctricas instaladas por FHIA, de forma automática, requiriendo únicamente de un análisis topográfico del perfil, que puede llevarse a cabo mediante un GPS o de forma más tradicional utilizando un mapa de curvas de nivel. 


\subsection{Optimización mediante algoritmos evolutivos}

A pesar del buen rendimiento del algoritmo propuesto en el apartado anterior, quedan algunas limitaciones inherentes al mismo que pueden ser consideradas de relevancia en ciertos casos. en primer caso, el coste computacional de la estrategia propuesta crece exponencialmente con el número de puntos. Si bien se ha demostrado que no es necesario hacer una discretización demasiado densa, sí que puede resultar un problema si se consideran longitudes de río muy altas. En segundo lugar, el diámetro de la tubería ha sido considerado fijo, puesto que así se considera en los proyectos de electrificación de FHIA debido a la disponibilidad. no obstante, en los casos en que resulte interesante evaluar diferentes diámetros de tubería para la instalación sería necesario lanzar el algoritmo con diferentes diámetros, puesto que la dependencia altamente no lineal del diámetro, $D p$, en las pérdidas (como se puede ver en las ecuaciones del modelo, donde aparece elevado a la quinta potencia en un denominador) no permite su consideración como variable de optimización sin sacrificar la linealidad del problema. Ante esta situación, se propone el desarrollo de un método meta-heurístico para resolver el problema no lineal resultante de considerar el diámetro de la tubería, $D p$, como variable. Debido a su gran capacidad para resolver problemas de ingeniería (Das et al., 2015; Nayak et al., 2018), se decide utilizar un algoritmo genético para resolver el problema. Una ventaja adicional de estos algoritmos es que permiten estudiar el problema de forma multi-objetivo (MO) además del modo de único objetivo (SO).

\subsection{Algoritmos Genéticos}

Los algoritmos genéticos son métodos meta-heurísticos (Alvarado-Barrios et al., 2019; Anagnostopoulos y Papantonis, 2007; Ehteram et al., 2018) que se basan en la ley de la evolución de Darwin, que estipula que aquellos individuos mejor adaptados al medio tienen más probabilidad de dejar descendencia. Básicamente, el funcionamiento de un algoritmo genético es el representado en la Figura 13, y que se explica a continuación.

En primer lugar, se decide una codificación de cada posible solución en forma de un vector denominado cromosoma, cuyos elementos (genes) contienen todas las variables de la solución. 


\section{FIGURA I3. Esquema básico de un algoritmo genético}

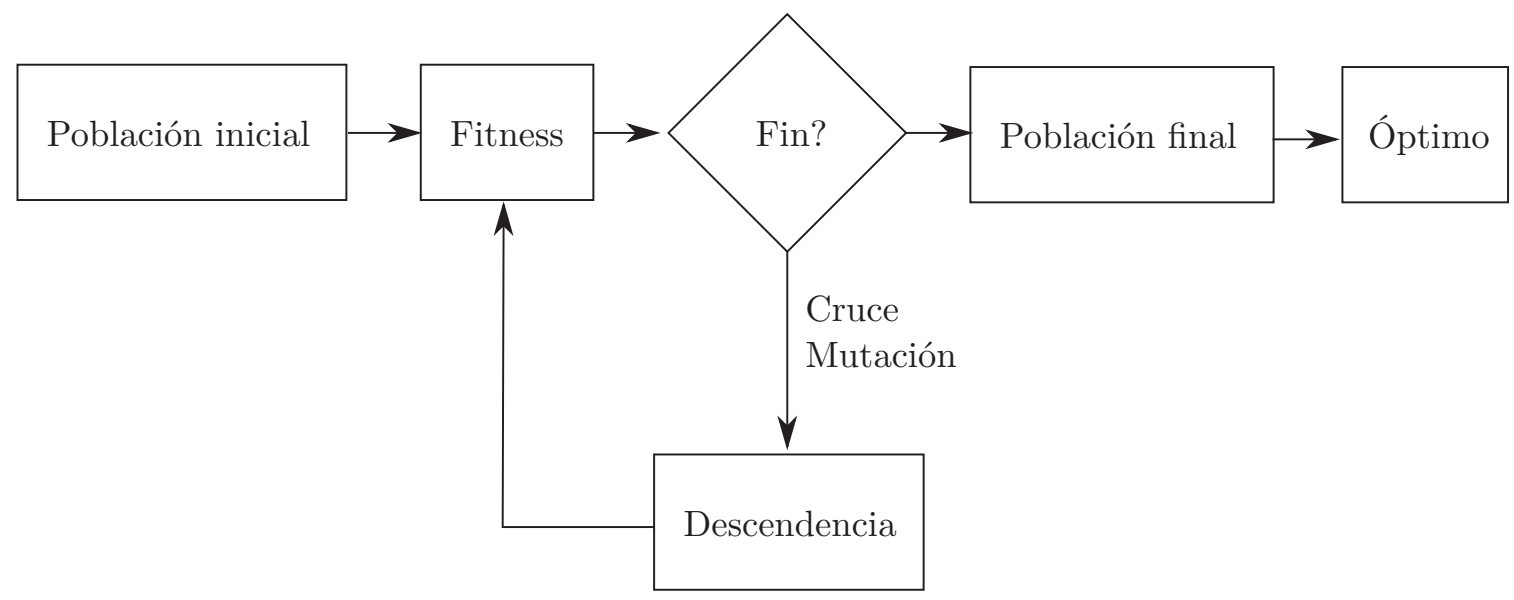

En segundo lugar, se genera una población inicial formada por una serie de individuos (soluciones) generados de forma aleatoria. A cada uno de estos individuos se le asigna un indicador de calidad denominado fitness, que no es más que el valor correspondiente de la función objetivo, y que va a representar su adaptación al medio.

A continuación, en función del fitness de los individuos, se genera una nueva población (descendencia) mediante una serie de operaciones heurísticas denominadas mutación y cruce. Una mutación consiste en generar un nuevo individuo modificando ciertos genes de otro. El cruce consiste en crear un individuo combinando la información genética de dos individuos (progenitores). Mediante un proceso de selección, se crea la población correspondiente a la siguiente generación a partir de individuos pertenecientes a la generación anterior y a su descendencia.

\subsubsection{Formulación discreta}

En primer lugar, se propone implementar un algoritmo genético que resuelva el problema de optimización en los mismos términos en que se ha definido en el apartado anterior. Para ello se decide utilizar cromosomas binarios formados por $N+5$ genes, de manera que los $N$ primeros genes representan las $N$ variables $\delta i$ definidas anteriormente, y los 5 últimos genes representan el diámetro de la tubería en base binaria, tal como se representa en al Figura 14. Esta estrategia resulta en $25=32$ combinaciones enteras de diámetros expresados en centímetros (desde 1 hasta $32 \mathrm{~cm}$ ). 
FIGURA 14. Codificación discreta de los individuos

1
\begin{tabular}{|l|l|l|l|l|l|l|l|l|l|l|l|l|l|}
\hline 0 & 1 & 1 & 0 & 1 & $\cdots$ & 1 & 0 & 0 & 0 & 1 & 0 & 0 & 1 \\
\hline
\end{tabular}

Trazado de la planta $[1, \mathrm{~N}]$

Diámetro $\lceil\mathrm{N}+1, \mathrm{~N}+5\rceil$

FIGURA 15. Esquema de generación de individuos propuesto para el algoritmo genético discreto

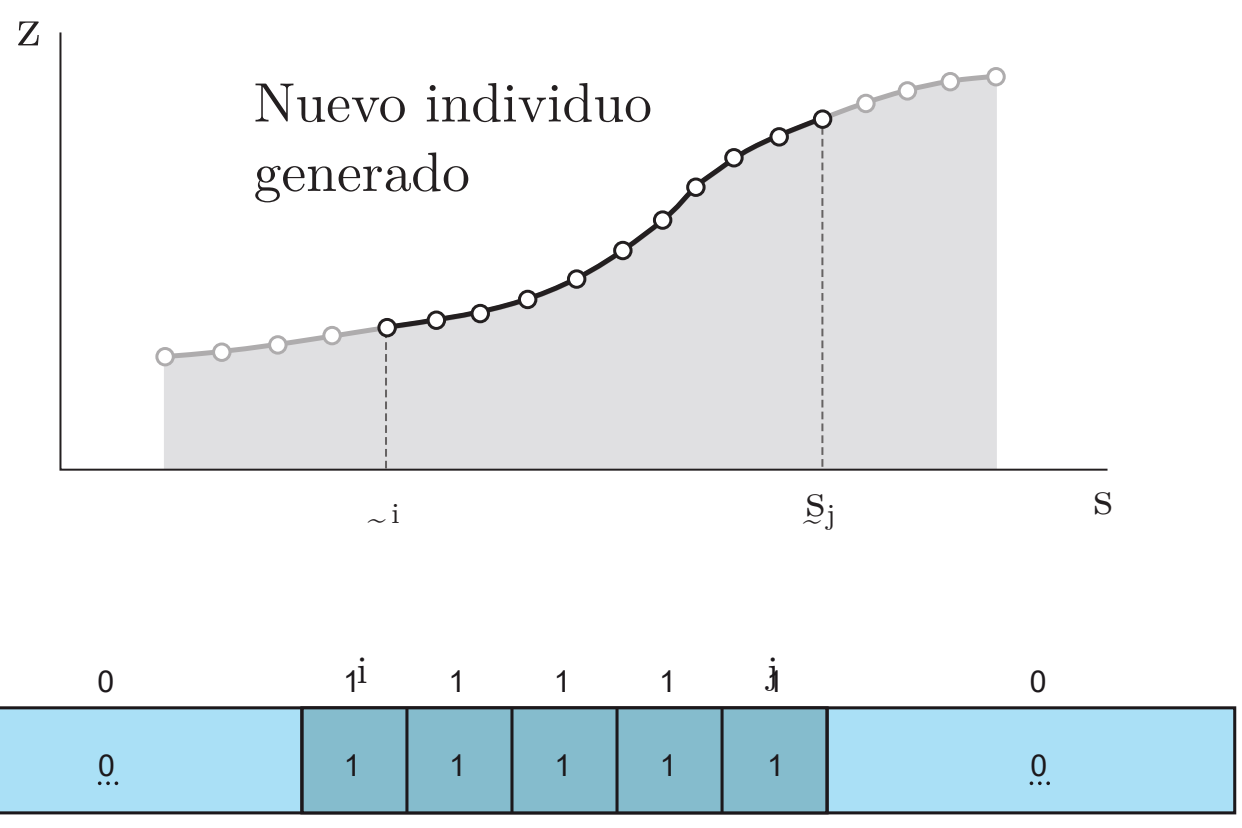

\subsubsection{Formulación del algoritmo genético}

Para generar la población inicial, dado que las restricciones de adaptabilidad al terreno son muy estrictas, se propone un método de generación orientado, de manera que los individuos generados satisfagan estas restricciones. La estrategia desarrollada consiste en escoger dos puntos aleatorios del conjunto de puntos de la discretización, y crear un individuo rellenando con nodos todos los puntos pertenecientes al intervalo definido entre ellos (ver Figura 15, de manera que la condición de adaptabilidad se satisface trivialmente.

Como función de fitness en el caso de un único objetivo se define el coste de la instalación correspondiente, para aquellos individuos factibles (esto es, que cum- 
plan los requisitos de potencia, caudal y adaptabilidad), y un valor infinito para el resto, de manera que el algoritmo tienda a descartar a los individuos no factibles. Para el caso multi-objetivo, a la función de fitness se añade simultáneamente la maximización de la potencia.

Para el operador de cruce, se propone combinar una fracción la información genética de los progenitores definida entre dos puntos de su cromosoma, como se muestra en la Figura 16-izquierda.

En cuanto a la mutación se ha escogido la operación de bit-flip modificado, como se representa en la Figura 16-derecha. El bit-flip consiste en invertir el valor genético de uno o más genes binarios. La modificación consiste en establecer una probabilidad más alta para el bit-flip de descenso (convertir un 1 a un 0) que para el de ascenso (convertir un 0 en un 1). Esto se introduce para estimular en el algoritmo la eliminación de nodos en las soluciones. Además, con la estrategia de creación de individuos iniciales propuesta, se espera que las poblaciones iniciales tengan un alto número de nodos.

\section{FIGURA 16. Operadores de cruce de dos puntos (izquierda) y mutación (derecha) propuestos para el algoritmo genético discreto}

Progenitores

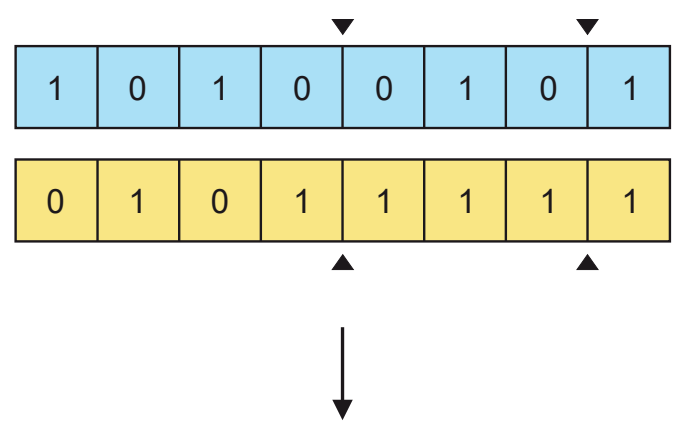

Descendencia

\begin{tabular}{|l|l|l|l|l|l|l|l|}
\hline 1 & 0 & 1 & 0 & 1 & 1 & 1 & 1 \\
\hline 0 & 1 & 0 & 1 & 0 & 1 & 0 & 1 \\
\hline
\end{tabular}

Progenitor

\begin{tabular}{|l|l|l|l|l|l|l|l|}
\hline 0 & 1 & 0 & 1 & 1 & 1 & 0 & 1 \\
\hline
\end{tabular}

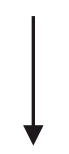

Descendencia

\begin{tabular}{|l|l|l|l|l|l|l|l|}
\hline 0 & 1 & 0 & 1 & 1 & 0 & 0 & 1 \\
\hline
\end{tabular}

Por último, se propone el mecanismo de torneo para la selección. Este mecanismo consiste en extraer de forma aleatoria a un conjunto de un determinado tamaño 
de individuos y elegir al mejor de ellos. Un tamaño de torneo de 3 ha demostrado dar buenos resultados en un amplio rango de problemas (Luke, 2009).

Para la implementación del modo de un único objetivo se ha escogido un esquema mupluslambda, consistente en una población de tamaño $\mu$ y una descendencia de tamaño $\lambda$, de manera que el pool de selección tiene tamaño $\mu+\lambda$. Esta estrategia otorga cierto elitismo al algoritmo, ya que los hijos tienen que competir con los padres. En cuanto al multi-objetivo, se ha escogido el algoritmo NSGA - II, que está basado en la Pareto-dominancia, gracias a la cual se obtiene el frente de Pareto del problema en cuestión, con el objetivo de obtener un mejor estudio del potencial del emplazamiento de la planta micro-hidráulica en fases de selección de la micro-cuenca. En (Tapia et al., 2019) se pueden consultar en detalle el desarrollo del algoritmo propuesto, así como su proceso de ajuste para obtener el mejor rendimiento.

\subsubsection{Aplicación a un caso de ejemplo}

El algoritmo genético propuesto se implementa en Python deap, y se utiliza para resolver el caso de ejemplo introducido anteriormente para evaluar su capacidad. Los casos estudiados se listan en la Tabla 3.3.2, mostrándose los resultados obtenidos en la Tabla 3.3.2. Se muestran además, en la Figura 17, las plantas óptimas correspondientes a estas soluciones.

\section{TABLA 3. Casos propuestos para la resolución del problema de ejemplo mediante el algoritmo genético discreto}

\begin{tabular}{|c|l|c|c|c|c|c|c|}
\hline Caso & \multicolumn{1}{|c|}{ Fun. obj. } & Modo & $\begin{array}{c}P_{\min } \\
(\mathrm{kW})\end{array}$ & $\lambda_{c}(\mathrm{~m})$ & $\begin{array}{c}\epsilon_{\text {sup }} \\
(\mathrm{m})\end{array}$ & $\begin{array}{c}\epsilon_{\text {exc }} \\
(\mathrm{m})\end{array}$ & $\begin{array}{c}D_{p} \\
(\mathrm{~cm})\end{array}$ \\
\hline 1 & $\min C_{p}$ & $\mathrm{SO}$ & 8.0 & 50 & 1.5 & 1.5 & 20 \\
\hline 2 & $\min C_{p}$ & $\mathrm{SO}$ & 8.0 & 0 & 1.5 & 1.5 & 20 \\
\hline 3 & $\min C_{p}$ & $\mathrm{SO}$ & 8.0 & 50 & 1.5 & 1.5 & Var. \\
\hline 4 & $\min C_{p}, \max P$ & $\mathrm{MO}$ & 8.0 & 50 & 1.5 & 1.5 & Var. \\
\hline
\end{tabular}

En cuanto al modo multi-objetivo, ha permitido obtener el frente de Pareto mostrado en la Figura 18. 
Observando los resultados se puede comprobar que, incluso fijando el diámetro de la tubería, el algoritmo genético consigue mejores soluciones mejores (aunque la diferencia no es sustancial, en torno al $3 \%$ de ahorro en coste). por supuesto, la consideración del diámetro como variable de decisión permite al algoritmo genético obtener un ahorro muy notable en el coste de las plantas micro-hidroeléctricas con respecto a la solución obtenida con la programación entera (67\%).

En cuanto al estudio del frente de Pareto, éste permite un análisis más exhaustivo del potencial del terreno, permitiendo determinar la sensibilidad de las posibles plantas a variaciones en la potencia instalada. En particular se pueden observar dos tendencias claras en el frente de Pareto.

\section{FIGURA 17. Soluciones obtenidas para el problema de ejemplo mediante el algoritmo genérico discreto (DGA) y mediante ramificación y poda (BBA)}

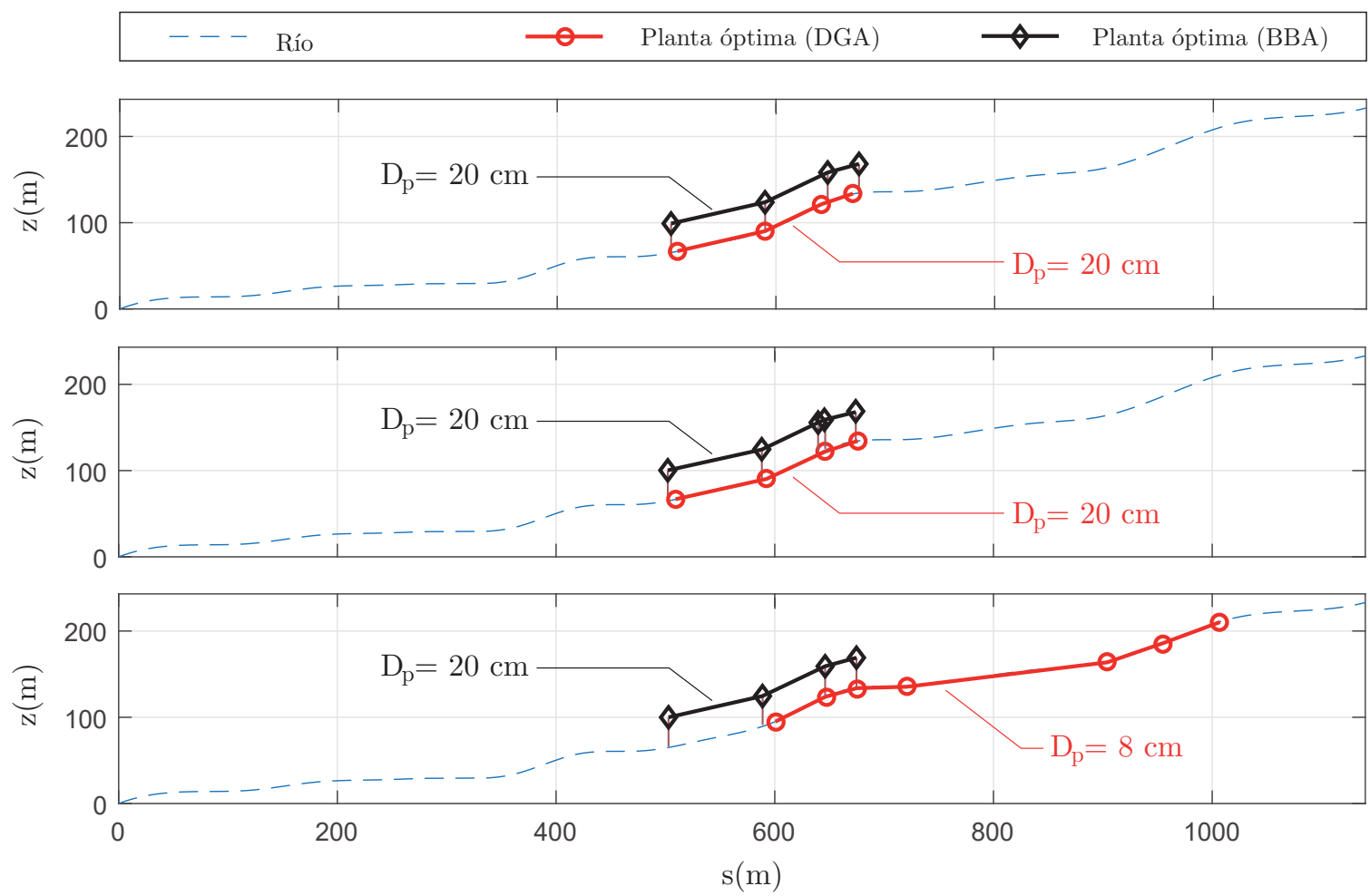

En primer lugar, se puede apreciar una tendencia aproximadamente lineal de las soluciones en la parte izquierda del frente de Pareto, de la que se puede determinar el coste marginal de aumentar la potencia instalada de la planta como la pendiente de la recta de regresión. De un análisis numérico se puede obtener una pendiente 
TABLA 4. Soluciones obtenidas en la resolución del problema de ejemplo mediante el algoritmo genético discreto (DGA) y comparación con ramificación y poda (BBA)

\begin{tabular}{|c|c|c|c|c|c|c|}
\hline \multirow{2}{*}{\multicolumn{2}{|c|}{$\begin{array}{l}\text { Caso } \\
\text { Método }\end{array}$}} & \multicolumn{2}{|c|}{1} & \multicolumn{2}{|c|}{2} & \multirow{2}{*}{$\begin{array}{c}3 \\
D G A\end{array}$} \\
\hline & & DGA & BBA & DGA & BBA & \\
\hline \multirow{2}{*}{ Parámetros } & $p c x$ & 0.80 & - & 0.80 & - & 0.60 \\
\hline & pmut & 0.20 & - & 0.20 & - & 0.40 \\
\hline \multirow{2}{*}{$\begin{array}{l}\text { Población } \\
\text { final }\end{array}$} & Fitness medio & 10628 & - & 11059 & - & 3846 \\
\hline & Desv. típica & 334 & - & 698 & - & 808 \\
\hline \multirow{7}{*}{$\begin{array}{l}\text { Mejor } \\
\text { individuo }\end{array}$} & $\mathrm{Hg}(\mathrm{m})$ & 66.648 & 69.124 & 66.648 & 69.124 & 115.642 \\
\hline & $Q(1 / s)$ & 13.72 & 13.98 & 13.72 & 13.98 & 13.71 \\
\hline & $\operatorname{Lp}(\mathrm{m})$ & 174.92 & 186.60 & 174.90 & 186.60 & 429.10 \\
\hline & nc & 4 & 4 & 4 & 5 & 7 \\
\hline & $P(k W)$ & 8.04 & 8.05 & 8.06 & 8.05 & 8.03 \\
\hline & $\mathrm{Dp}(\mathrm{cm})$ & 20.00 & 20.00 & 20.00 & 20.00 & 8.00 \\
\hline & $C(k \$)$ & 10.50 & 10.83 & 10.50 & 12.23 & 3.49 \\
\hline
\end{tabular}

FIGURA 18. Frente de Pareto del problema de ejemplo obtenido mediante el algoritmo genérico discreto (DGA)

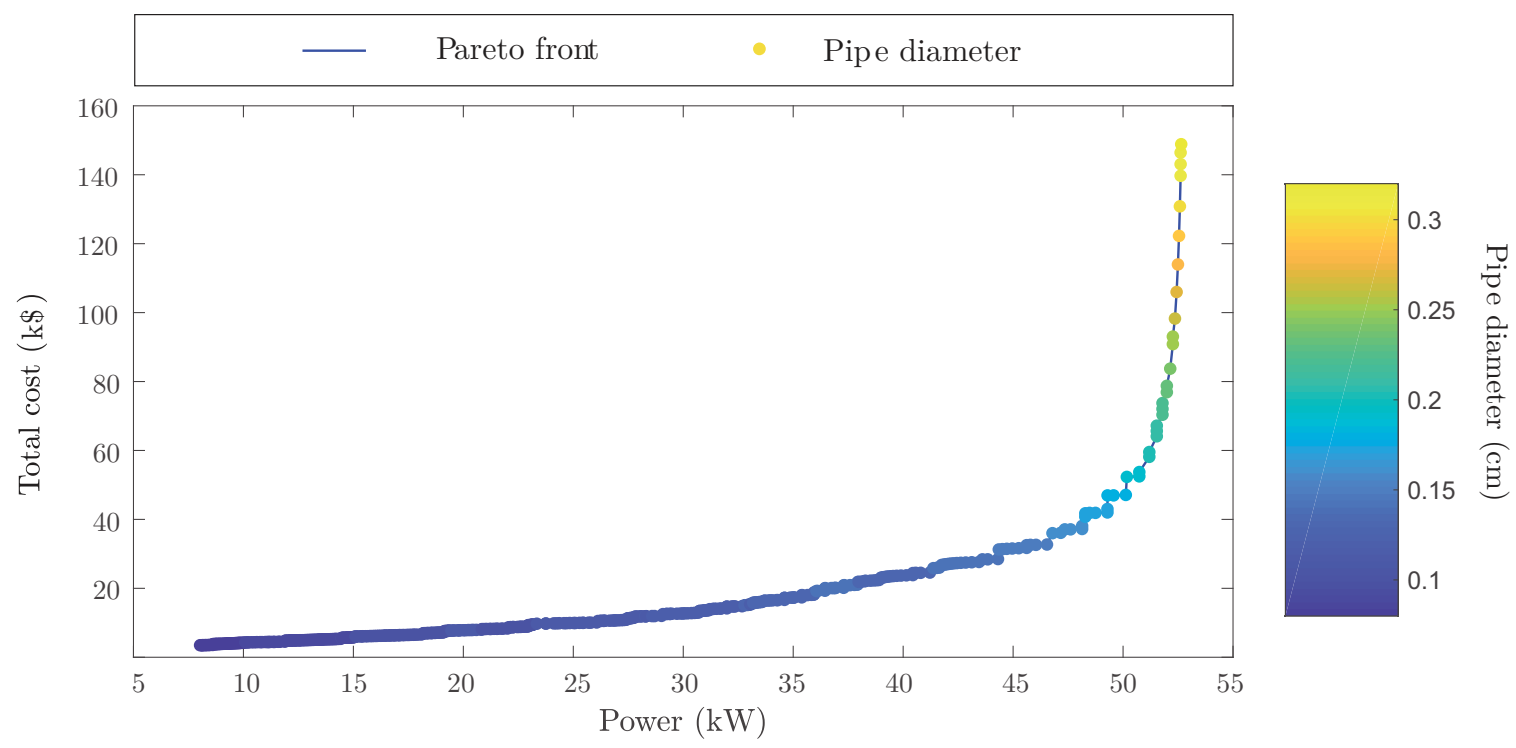


de $\$ 290.1$ por $\mathrm{kW}$ de potencia adicional. Esto equivale a decir que incrementar la potencia de la planta en un $10 \%$ requiere incrementar el coste en un $6.65 \%$.

En cuando a la parte derecha del gráfico, se puede observar una asíntota vertical, cuya primera hipótesis responde a una saturación del dominio del terreno, ante la cual sólo se puede incrementar la potencia incrementando el diámetro en lugar de extendiendo la tubería forzada. Para validar esta hipótesis, se considera una planta micro-hidroeléctrica que explotase la máxima altura neta disponible sin pérdidas. las características de dicha planta vendrían definidas por:

$$
\left\{\begin{array}{l}
H^{*} g=233,026 \mathrm{~m} \\
L^{*} p=0 \mathrm{~m} \\
D^{*}{ }_{p}=32 \mathrm{~cm}
\end{array}\right.
$$

Sustituyendo estos valores en las ecuaciones del modelo introducidas al principio de este documento, se obtiene que la potencia máxima extráıble $P^{*}$ sería:

$$
P^{*}=52,88 \mathrm{~kW},
$$

que efectivamente coincide con la localización de la asíntota en la gráfica, con lo que la hipótesis queda validada.

\subsubsection{Formulación continua}

Aunque está claro que el método meta-heurístico propuesto presenta unas ventajas muy claras frente a la programación entera, la estrategia utilizada no es quizás la más adecuada, considerando que se ha utilizado una geometría del problema que se formuló con el propósito de aplicar el algoritmo de ramificación y poda. Por este motivo, la naturaleza discreta del problema sigue representando un inconveniente que puede ser de gran relevancia en una aplicación real, donde debido a las limitaciones técnicas, es posible que el estudio topográfico realizado por los técnicos locales sea de baja calidad. Esto se traduciría en una gran dispersión de densidades de resolución en diferentes áreas del terreno, es decir, es de esperar que existan zonas difícilmente accesibles en las que la discretización sea muy pobre. Así, está claro que la naturaleza discreta del problema no consideraría ciertas soluciones que podrían estar cerca del óptimo, ya que sólo se considera la instalación de nodos en los puntos discretizados. 
Partiendo de esta idea, se propone reformular el problema para considerar una formulación continua. Así, se propone utilizar una interpolación cúbica por tramos con conservación de forma (PCHIP), ésto es, una interpolación que evita la formación de valles y picos entre dos puntos consecutivos. Esto encaja con la naturaleza del perfil del río, de cuya pendiente se espera que no varíe su signo a lo largo de todo el trazado, pues el agua siempre seguirá una pendiente negativa - nula, pero nunca positiva. En la Figura 19 se muestra un ejemplo para ilustrar la ventaja de la interpolación PCHIP sobre al SPLINE tradicional.

\section{FIGURA 19. Ilustración de la conservación de forma que garantiza la interpolación mediante PCHIP o en comparación con el spline tradicional}

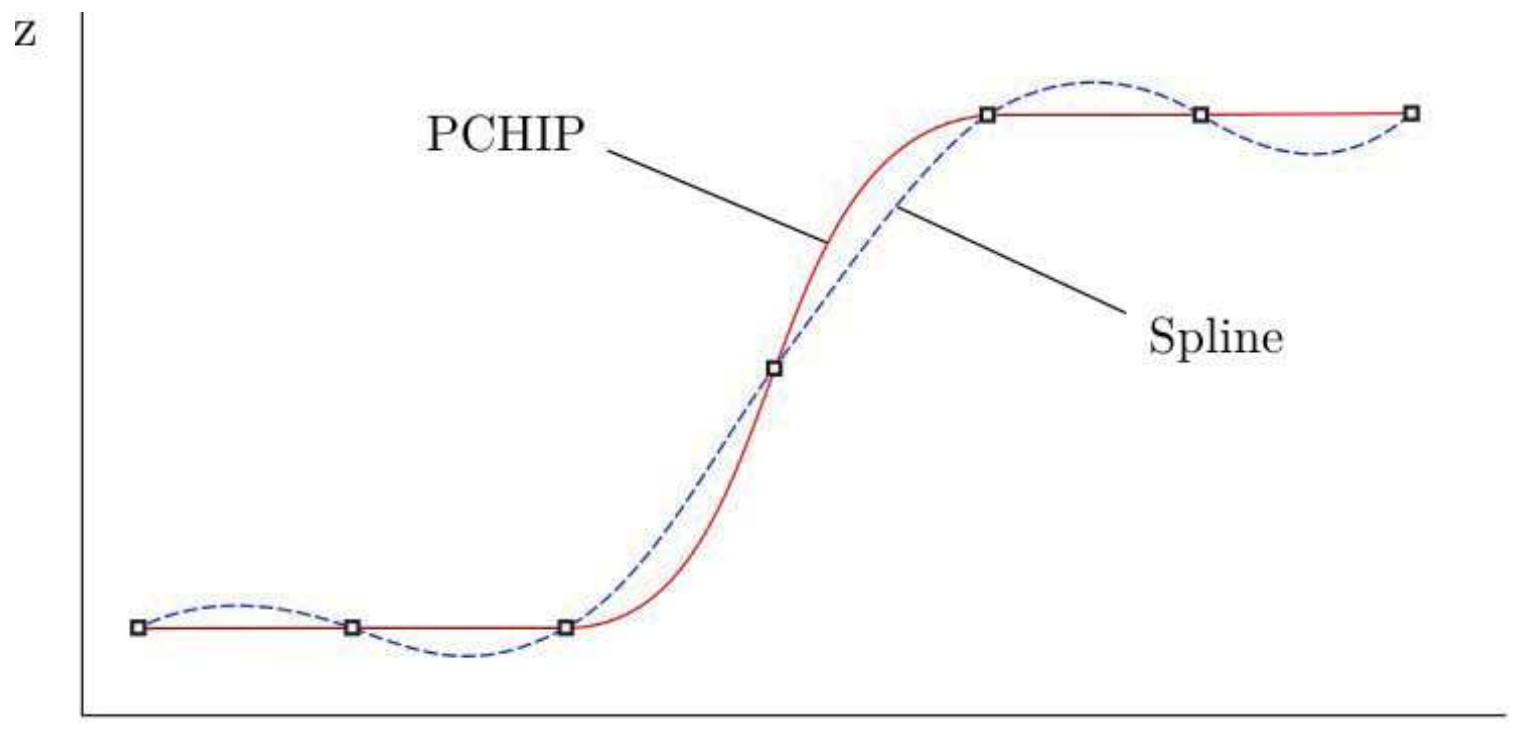

Partiendo de esta base, se plantea desarrollar algoritmo genético análogo al anterior pero considerando nodos que pueden ocupar cualquier posición a lo largo de la definición del río, como se muestra en la Figura 20. Nótese que el tamaño del cromosoma es, en este caso, variable, puesto que el número de nodos no está definido a priori.

De esta manera, se define un cromosoma de tamaño $M+1$, donde los primeros $M$ genes se corresponden con la posición de $M$ nodos (en el ejemplo de la Figura $20, M=3$ ), y el último gen, $M+1$ se corresponde con el diámetro de la tubería, siendo todos los nodos definidos como variables continuas (véasé la Figura 21). 


\subsubsection{Formulación del algoritmo genético}

La generación de la población inicial se hace de nuevo orientada (representado en la Figura 22), con el fin de generar individuos que satisfagan de forma trivial la restricción de adaptabilidad al terreno. Se ha diseñado un algoritmo basado en escoger aleatoriamente la ubicación de la turbina (nodo inicial) e incorporar nodos adicionales sucesivamente (de tal forma que no se viole la adaptabilidad) hasta que la planta resultante satisfaga la generación de potencia demandada. De esta forma se estimula la admisibilidad de los individuos en las primeras generaciones, facilitando una buena exploración del espacio de búsqueda. Nótese que es necesario establecer a priori un valor máximo del primer nodo $x 1$ para el cual es posible el desarrollo anterior.

\section{FIGURA 20. Formulación continua del problema}

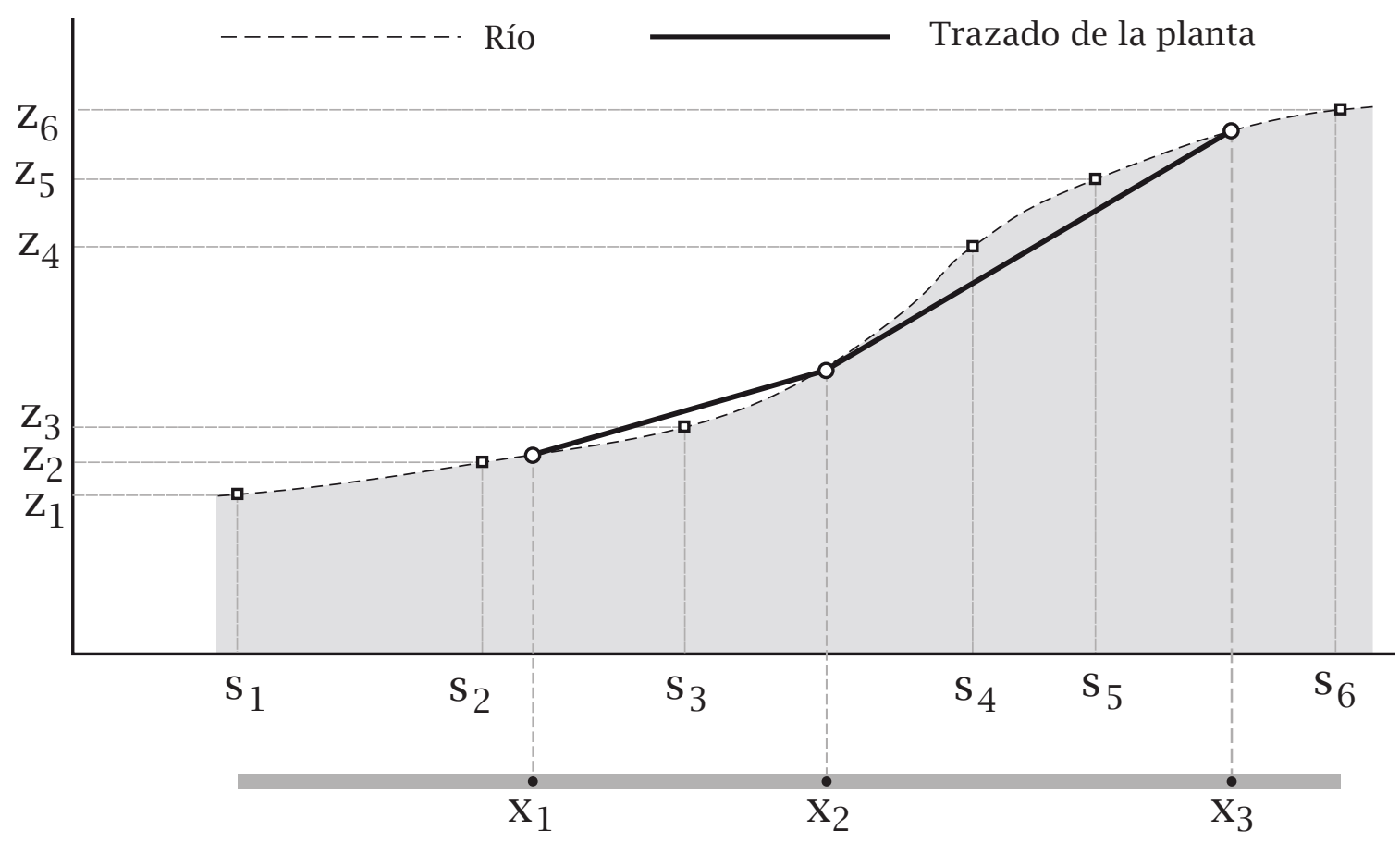

FIGURA 2I. Codificación continua de los individuos

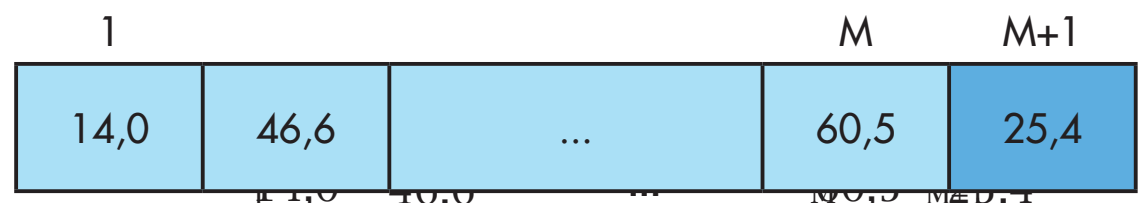

Trazado de la planta $[1, M] \quad$ Diámetro $[M+1]$ 
Para la operación de cruce, puesto que ahora los individuos progenitores pueden tener diferente tamaño, se propone una operación de cruce difuso (representado en la Figura 23-izq.), consistente en extender el individuo más pequeño al tamaño del más grande y promediar el valor de cada par de genes para la descendencia.

En cuanto a la mutación, se propone un esquema de mutación gaussiana (representado en la Figura 23-dcha.), mediante el cual los genes mutados se desplazan de forma continua una determinada distancia cuyo valor obedece a una distribución gaussiana con media en el valor inicial del gen.

\section{FIGURA 22. Esquema de generación de individuos propuesto para el algoritmo genético continuo}

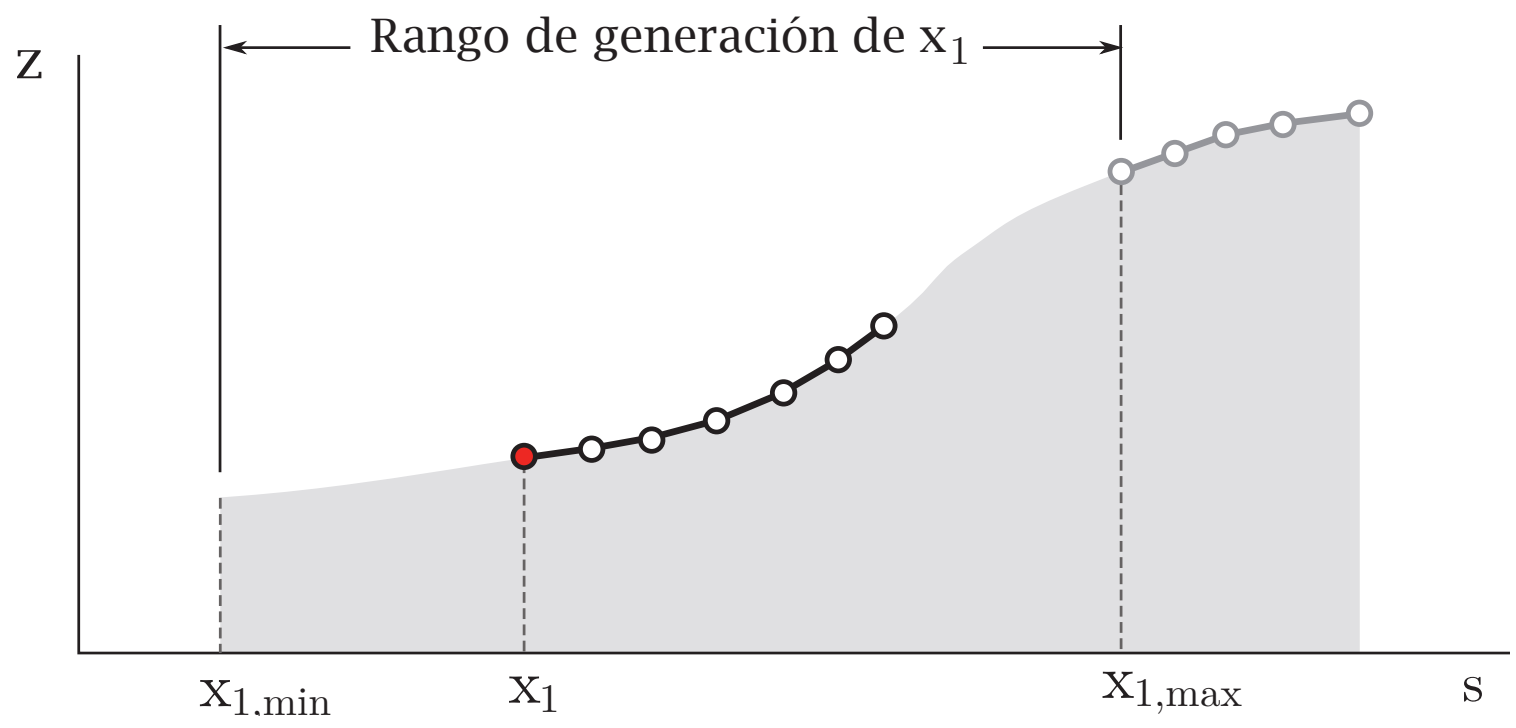

Para la selección, se propone de nuevo el mecanismo de torneo de tamaño 3 para la selección, en base a los buenos resultados obtenidos con el algoritmo anterior. De forma análoga al caso anterior, se ha escogido un esquema mupluslambda para el modo de un único objetivo y el algoritmo NSGA - Il para el multi-objetivo. 


\section{FIGURA 23. Operadores de cruce borroso (izquierda) y mutación gaussiana (derecha) propuestos para el algoritmo genético continuo}

progenitores

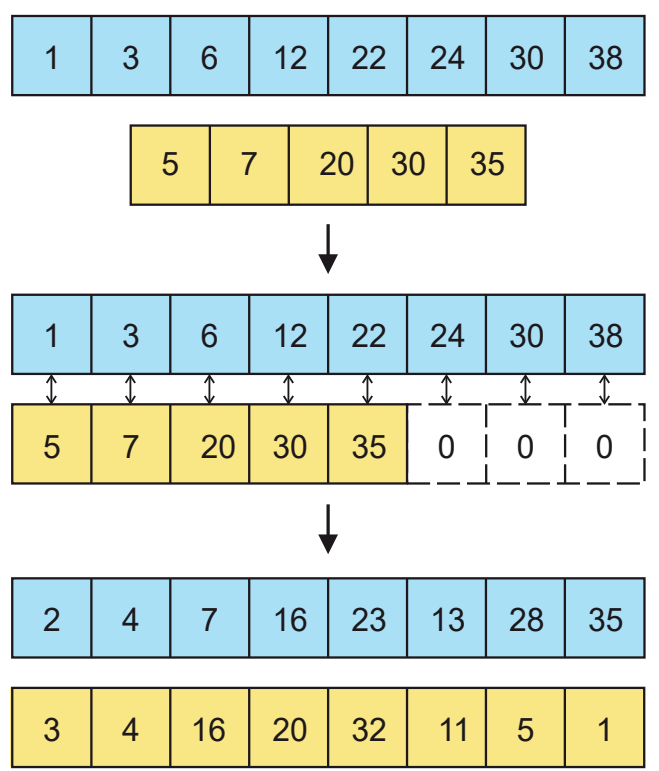

progenitor

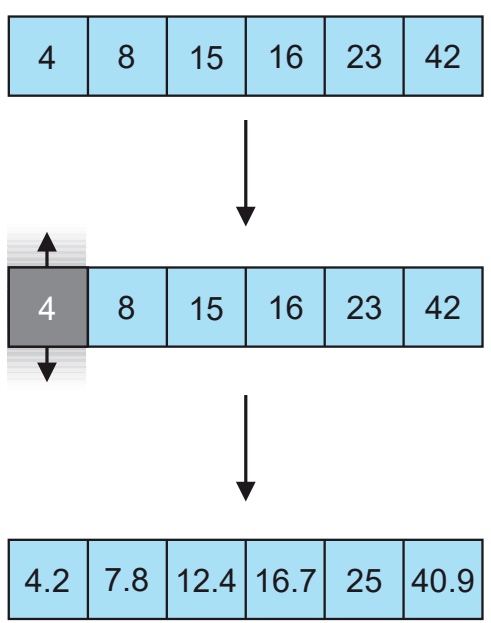

descendencia

descendencia

\subsubsection{Aplicación a un caso real}

Con el fin de de validar las ventajas del enfoque continuo frente al discreto que motivan el desarrollo de este algoritmo, se propone estudiar un perfil de río real obtenido mediante un análisis topográfico. Observando el perfil en la Figura 24 se puede apreciar que la discretización no es uniforme, y aparecen zonas de baja resolución, lo cual será interesante de cara a la comparación de los enfoques discreto y continuo. Además, se han representado en esta figura las interpolaciones resultantes del PCHIP y del SPLINE, de manera que se evidencian las ventajas del primero sobre el segundo, evitándose la formación de colinas que no corresponden a la naturaleza del perfil del río. 


\section{FIGURA 24. Perfil de río real utilizado para aplicar el algoritmo genético continuo}

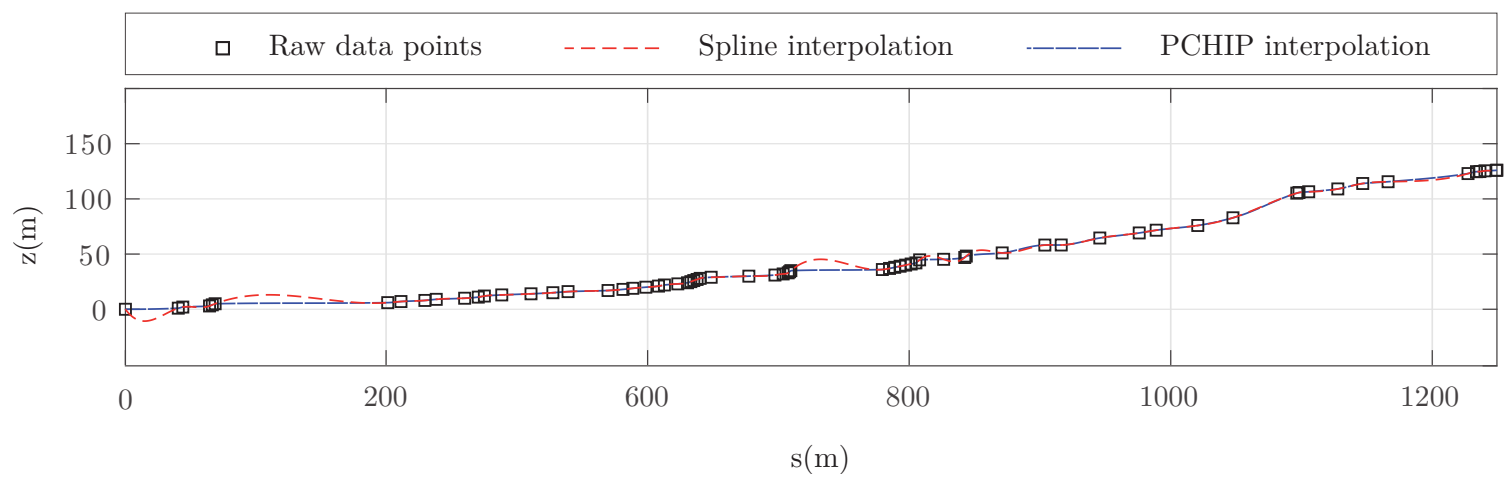

Para este problema se proponen los casos detallados en la Tabla 3.3.3, obteniéndose los resultados listados en la Tabla 3.3.3. En esta misma tabla se han incluido además los resultados obtenidos emdaainte el algoritmo genético discreto y la programación entera, anteriormente descritos, con el fin de validar las ventajas de este nuevo método. Además, en la Figura 25 se representan las plantas correspondientes a las soluciones obtenidas.

\section{TABLA 5. Casos propuestos para la resolución del problema de ejemplo mediante el algoritmo genético continuo}

\begin{tabular}{|c|l|c|c|}
\hline Caso & Función objetivo & Diámetro & Modo \\
\hline 1 & $\min C p$ & Variable & SO \\
\hline 2 & $\min C p$ & Fijado & $S O$ \\
\hline 3 & $\min C p, \max P$ & Variable & $M O$ \\
\hline
\end{tabular}

Análogamente al caso anterior, el modo multi-objetivo permite determinar el frente de Pareto del problema, que se representa en la Figura 26.

Observando los resultados, se puede comprobar el buen rendimiento de la extensión del problema a una formulación continua al aplicarse a una discretización de baja calidad. Este nuevo método permite obtener mejoras notables en las soluciones, que se traducen en un ahorro de hasta el $56.96 \%$ en el coste de la planta micro-hidroeléctrica con respecto a la obtenida mediante programación entera, y con una reducción de casi el $10 \%$ con respecto a la obtenida mediante el algoritmo genético discreto. 
FIGURA 25. Soluciones obtenidas para los dos casos estudiados (Casos I y 2, arriba y abajo, respectivamente) del problema real mediante el algoritmo genérico continuo (MGA)

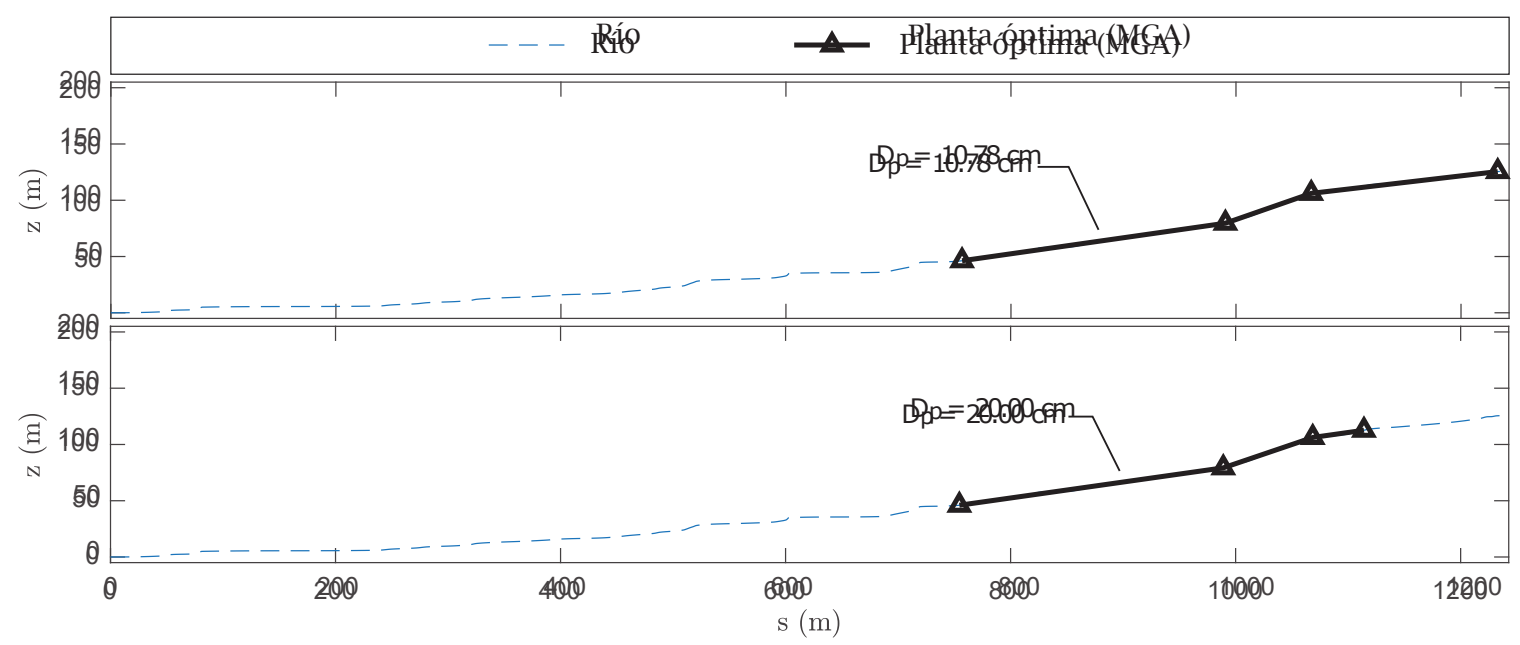

FIGURA 26. Frente de Pareto del problema real obtenido mediante el algoritmo genérico continuo (MGA)

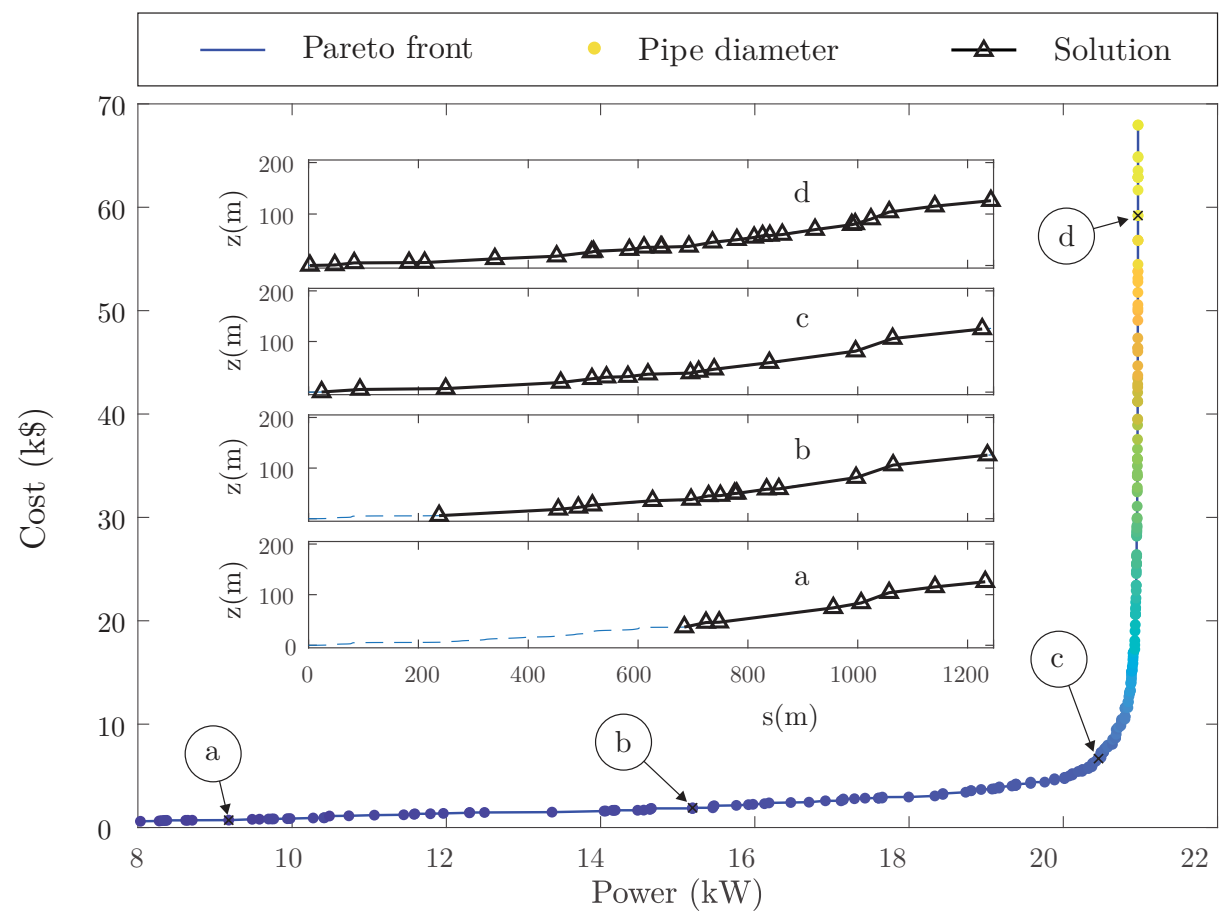

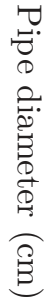


TABLA 6. Soluciones obtenidas en la resolución del problema real mediante el algoritmo genético continuo y comparación con el algoritmo genético discreto y con el método de ramificación y poda (BBA)

\begin{tabular}{|c|c|c|c|c|c|c|}
\hline \multirow{2}{*}{\multicolumn{2}{|c|}{$\begin{array}{l}\text { Caso } \\
\text { Approach }\end{array}$}} & \multicolumn{2}{|c|}{1} & \multicolumn{3}{|c|}{2} \\
\hline & & \multirow{2}{*}{$\begin{array}{l}\text { MGA } \\
0.50\end{array}$} & \multirow{2}{*}{$\begin{array}{l}\text { DGA } \\
0.60\end{array}$} & \multirow{2}{*}{$\begin{array}{l}\text { MGA } \\
0.50\end{array}$} & \multirow{2}{*}{$\begin{array}{l}\text { DGA } \\
0.60\end{array}$} & \multirow{2}{*}{ BBA } \\
\hline Parameters & $p_{c x}$ & & & & & \\
\hline & Pmut & 0.50 & 0.40 & 0.50 & 0.40 & - \\
\hline & $\sigma$ & 0.05 & - & 0.05 & - & - \\
\hline & $p_{\text {cut }}$ & 1.00 & - & 1.00 & - & - \\
\hline \multirow[t]{2}{*}{ Final population } & Meanfitness & 6036.1 & 7239.0 & 17152.0 & - & - \\
\hline & Std. dev. & 222.6 & 375.1 & 348.6 & - & - \\
\hline \multirow[t]{7}{*}{ Best individual } & $H_{g}(\mathrm{~m})$ & 79.26 & 77.76 & 66.66 & 67.37 & 64.71 \\
\hline & $Q(1 / s)$ & 13.75 & 13.74 & 13.70 & 13.77 & 13.50 \\
\hline & $L_{p}(m)$ & 484.08 & 471.74 & 366.86 & 389.57 & 376.00 \\
\hline & $n_{c}$ & 4 & 5 & 4 & 5 & 10 \\
\hline & $P(\mathrm{~kW})$ & 8.09 & 8.08 & 8.00 & 8.12 & 8.13 \\
\hline & $D_{p}(\mathrm{~cm})$ & 10.78 & 11.00 & 20.00 & 20.00 & 20.00 \\
\hline & $C_{p}(k \$)$ & 5.56 & 6.11 & 15.87 & 17.91 & 24.53 \\
\hline
\end{tabular}

Por último, un análisis análogo al realizado para el caso anterior permite estimar el coste marginal de la planta en \$1862 por kW de potencia instalada adicional. Esta información es especialmente relevante en la fase de selección de comunidad, y no puede ser obtenida mediante las estrategias de diseño tradicionales.

\subsection{Mejoras del equipamiento}

Adicionalmente al diseño de estrategias de optimización para asistir la toma de decisiones en el diseño de las plantas micro-hidroeléctricas, se han propuesto dos líneas de mejora en base a deficiencias observadas en el desarrollo de los proyectos. La primera de ellas hace referencia al proceso de fabricación de las turbinas, y la segunda a la instalación de un pequeño sistema de monitorización de la misma. 
FIGURA 27. Rodete de una turbina Pelton fabricada por FHIA

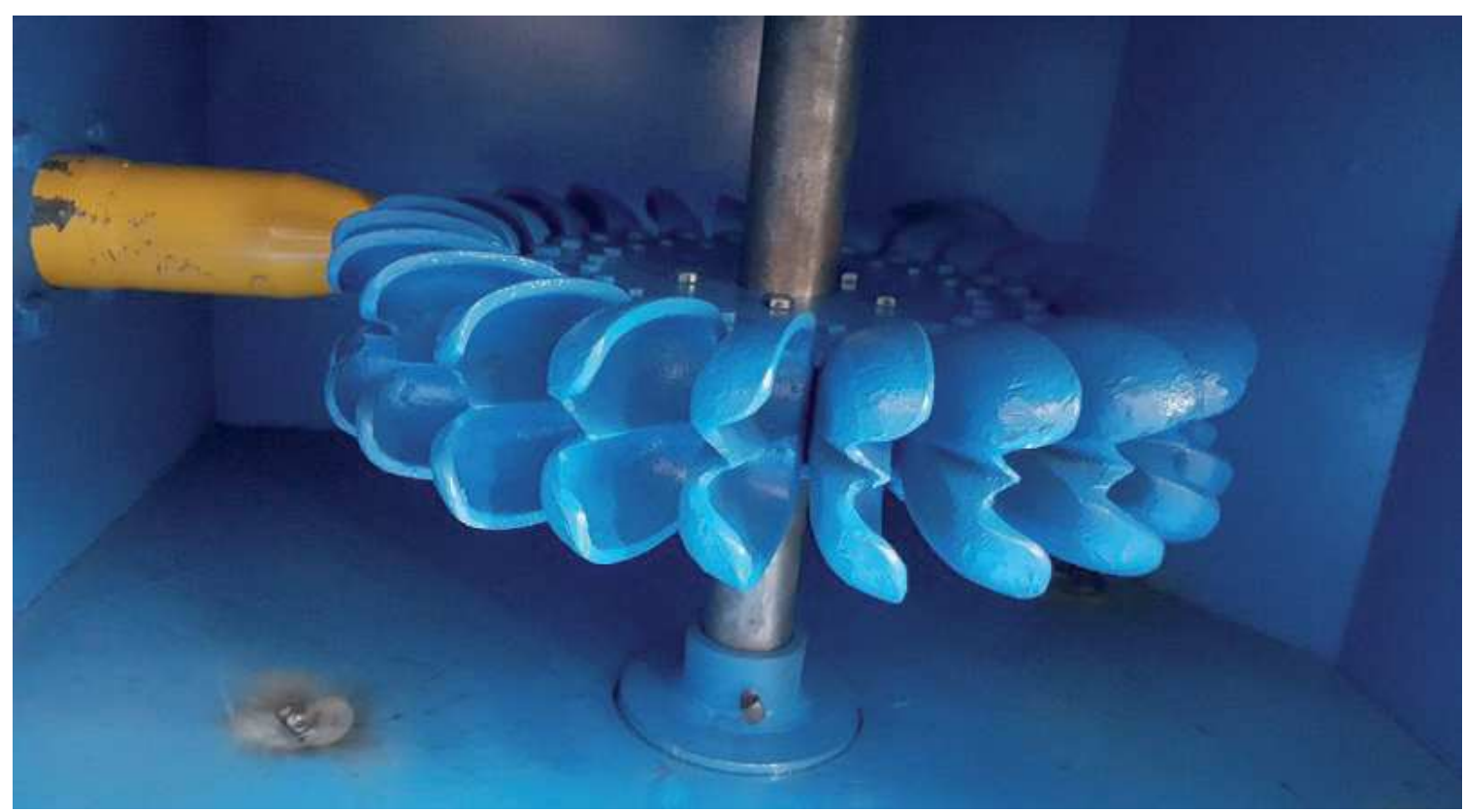

\subsection{Mejora del proceso de fabricación de las turbinas}

Si bien el rendimiento de las turbinas Pelton es especialmente alto frente a variaciones en las condiciones de funcionamiento, tales como variaciones de caudal o velocidad, su modo de funcionamiento (en el que un chorro de agua impacta la superficie interna de una serie de cucharas) las hace especialmente sensibles a depender del método de fabricación.

La fabricación de las turbinas instaladas por FHIA (Figura 27) se basa en la fundición de acero para replicar un modelo original. Este modelo original es tallado de forma manual en madera. Esto provoca, en primer lugar, que las dimensiones de las cucharas no responden a un proceso de diseño óptimo adaptado a las condiciones nominales de altura y caudal con las que va a funcionar la futura turbina. En segundo lugar, la naturaleza artesanal de la fabricación mediante tallado en madera provoca que las superficies curvas no tengan la curvatura y acabado ideal para minimizar el rozamiento del agua sobre ella, condicionando notablemente no sólo la eficiencia del sistema final sino también aspectos adicionales como las vibraciones o las averías.

En base a esto, se propone sustituir los modelos de madera por réplicas exactas del modelo teórico fabricadas en termoplástico mediante técnicas de fabricación 
aditiva. De esta forma no sólo los modelos fabricados en acero tendrán las dimensiones adecuadas sino que se incrementará la vida útil del modelo original, evitando la necesidad de fabricar nuevos.

\subsubsection{Mejora del sistema de monitorización}

Una de las problemáticas observadas y corroboradas por los técnicos de FHIA radica en las dificultades que implica supervisar el correcto funcionamiento de la planta. A lo largo del día se producen situaciones de exceso o falta de demanda que pueden provocar que el régimen de funcionamiento de la turbina se aleje del nominal. Puesto que la única manera de comprobar el estado del sistema es a través de la instrumentación instalada en la casa de máquinas, en aquellos emplazamientos en que ésta se instala a una gran distancia de la comunidad, la tarea de monitorización era poco viable, siendo por tanto imposible corregir comportamientos que pudieran desembocar en variaciones de tensión que dañasen los equipos eléctricos instalados en la comunidad.

Por ello, y ante la imposibilidad de instalar un sistema de control automático debido a la falta de recursos técnicos y económicos, se propone instalar un sistema económico de monitorización del sistema en la comunidad, de manera que no sea necesario visitar la instalación para comprobar todas las variables de interés relativas al régimen de funcionamiento del sistema (voltaje, corriente y frecuencia).

\section{Implementación de los resultados en un proyecto de elec- trificación rural de FHIA}

Como última parte del trabajo, se propone la validación de la metodología y mejoras propuestas en una comunidad piloto, de manera que pueda servir de referencia para su réplica en los posteriores proyectos de electrificación enmarcados en el programa Eco-Sistemas de FHIA.

\section{I. La comunidad de San Miguelito}

En Febrero de 2016 se lleva a cabo por parte de la Fundación ETEA y miembros de FHIA una evaluación de posibles comunidades piloto, que concluyó con la comunidad de San Miguelito como propuesta (Figura 28). 


\section{FIGURA 28. Visita de la Fundación ETEA y la Universidad Loyola Andalucía a la comunidad de San Miguelito}

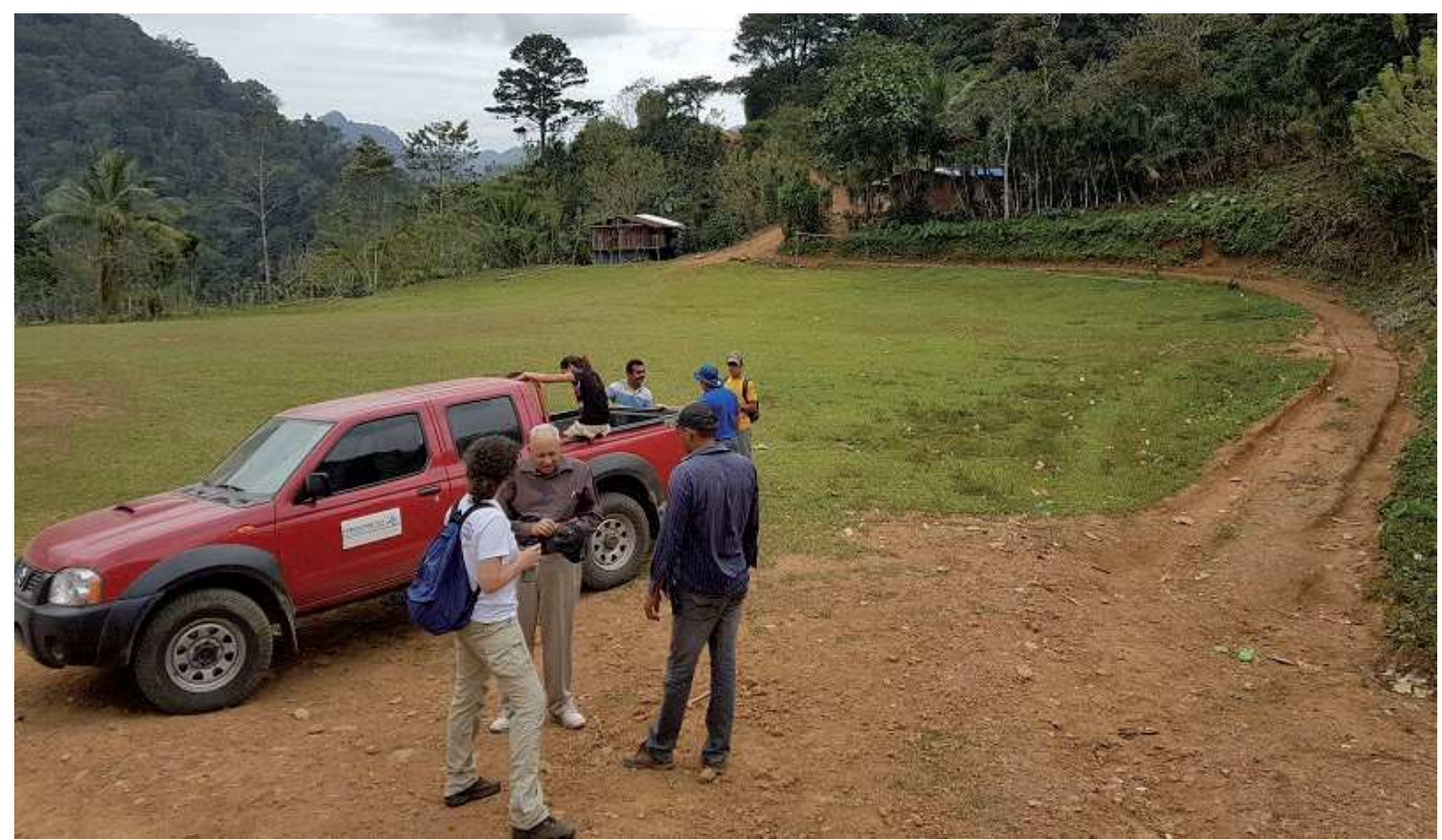

San Miguelito es una pequeña comunidad del departamento de Santa Bárbara, compuesto por unas 40 familias agricultoras. Las condiciones geográficas de esta comunidad son tales que no sólo su acceso a la red eléctrica no es en absoluto viable, sino que el propio acceso a la comunidad se imposibilita durante ciertas épocas del año debido a los cauces de agua provocados por las lluvias. Si bien, la cercanía a estos caudalosos ríos (véase la fotografía de la Figura 29) lo convertían en un emplazamiento ideal para desarrollar las estrategias propuestas e instalar un sistema micro-hidroeléctrico.

El análisis topográfico se llevó a cabo mediante un vuelo de dron de ala fija, permitiendo la obtención no sólo del perfil del río, sino también el levantamiento de curvas de nivel (en la Figura 30 se representa una fracción del mapa obtenido) que permitirán continuar el estudio con estrategias de diseño más avanzadas que requieran de información adicional, como la distribución de las casas o los accesos. Además, un análisis con estación total permitió realizar el levantamiento preciso del perfil del río, como se muestra en la Figura 31, junto con las ubicaciones de la casa de máquinas y la presa propuestas por FHIA. Éstas son consideradas como caso de referencia para evaluar los beneficios del método de optimización propuesto. 


\section{FIGURA 29. Río cercano a San Miguelito}

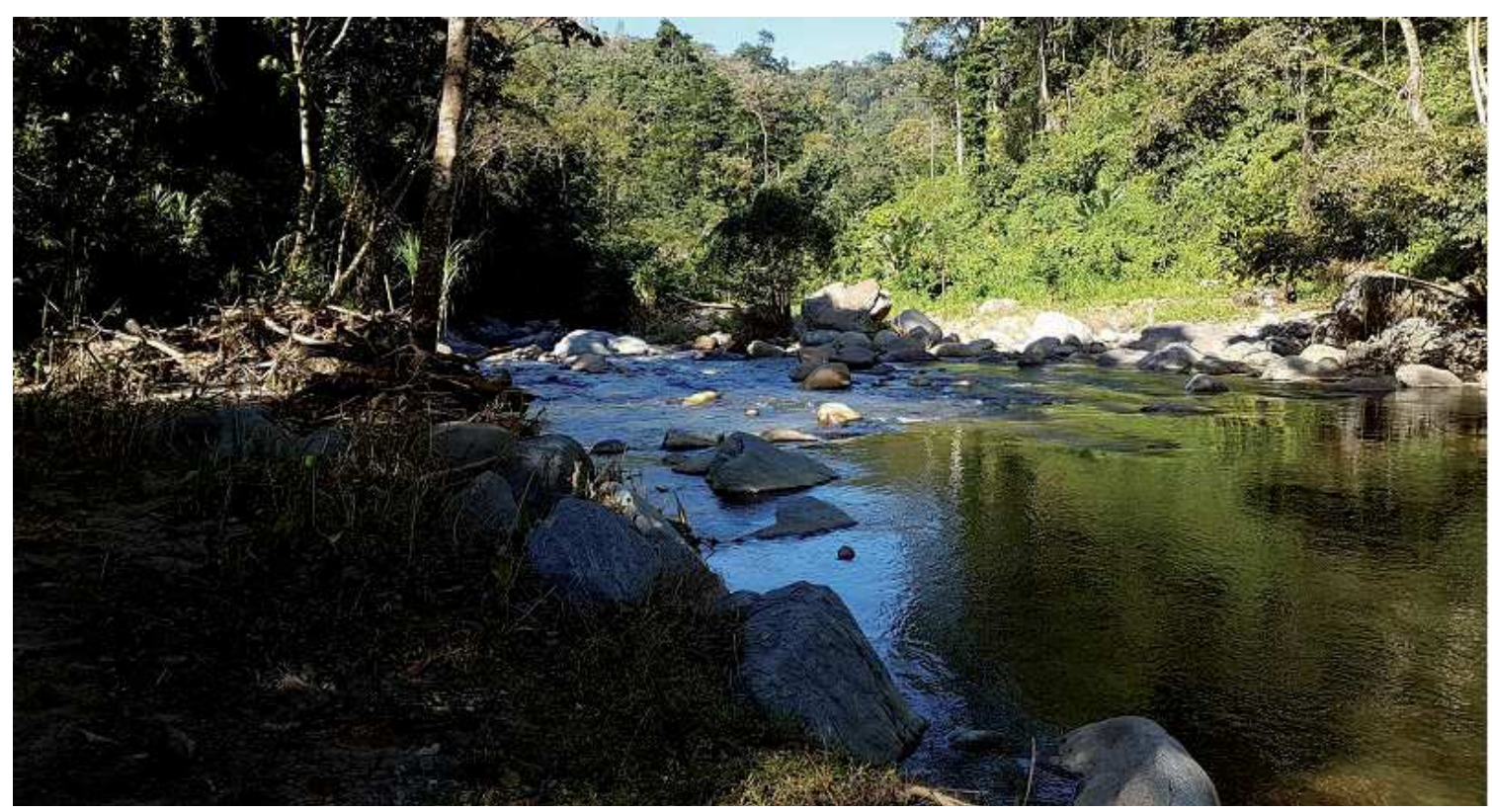

FIGURA 30. Fotografía aérea obtenida mediante un reconocimiento con un dron de ala fija

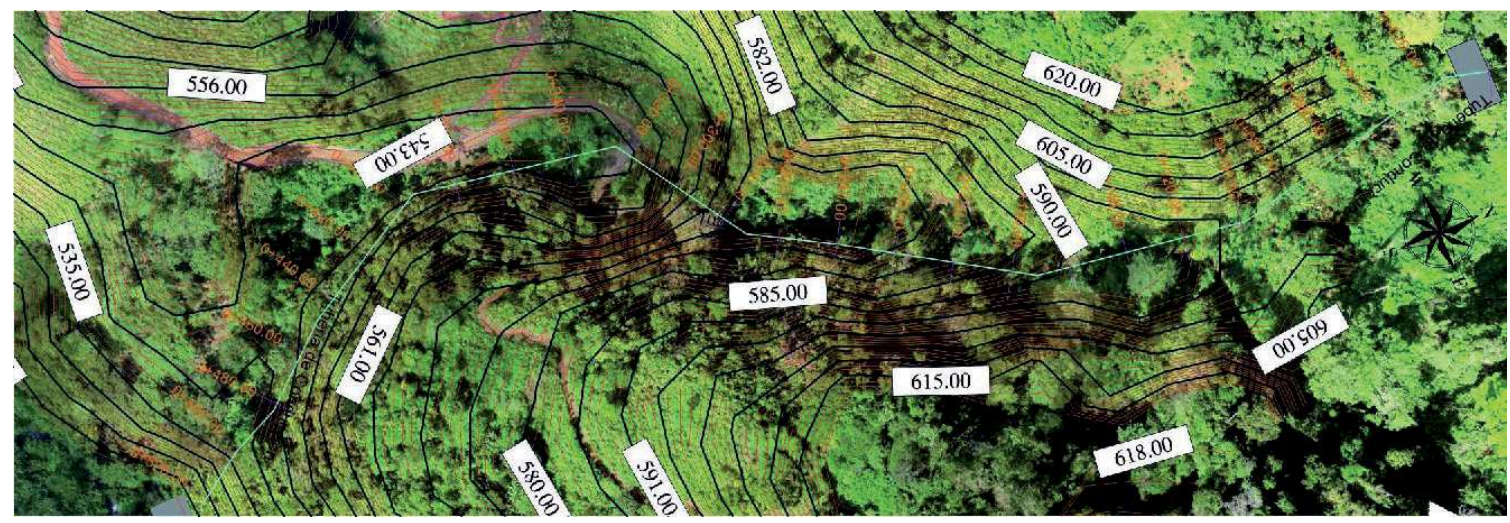

En base a la solución inicial propuesta por los técnicos de FHIA, se proponen los siguientes casos:

- Referencia: En este caso se fija la posición de la casa de máquinas y de la presa deacuerdo a las estimaciones de FHIA. No obstante, se utiliza el algoritmo de optimización para determinar la dsitribución más adecuada de segmentos y nodos del trazado. 
- Caso de mejora 1: Se resuelve el problema de optimización modificado, de forma que se persigue minimizar la longitud de la tubería manteniendo al menos la misma potencia generada que en la solución de referencia.

- Caso de mejora 2: Se resuelve el problema de optimización modificado, de forma que se persigue maximizar la potencia generada por la planta microhidroeléctrica sin incrementar el coste propuesto en la solución de referencia.

\section{FIGURA 3I. Perfil del río obtenido mediante estación total}

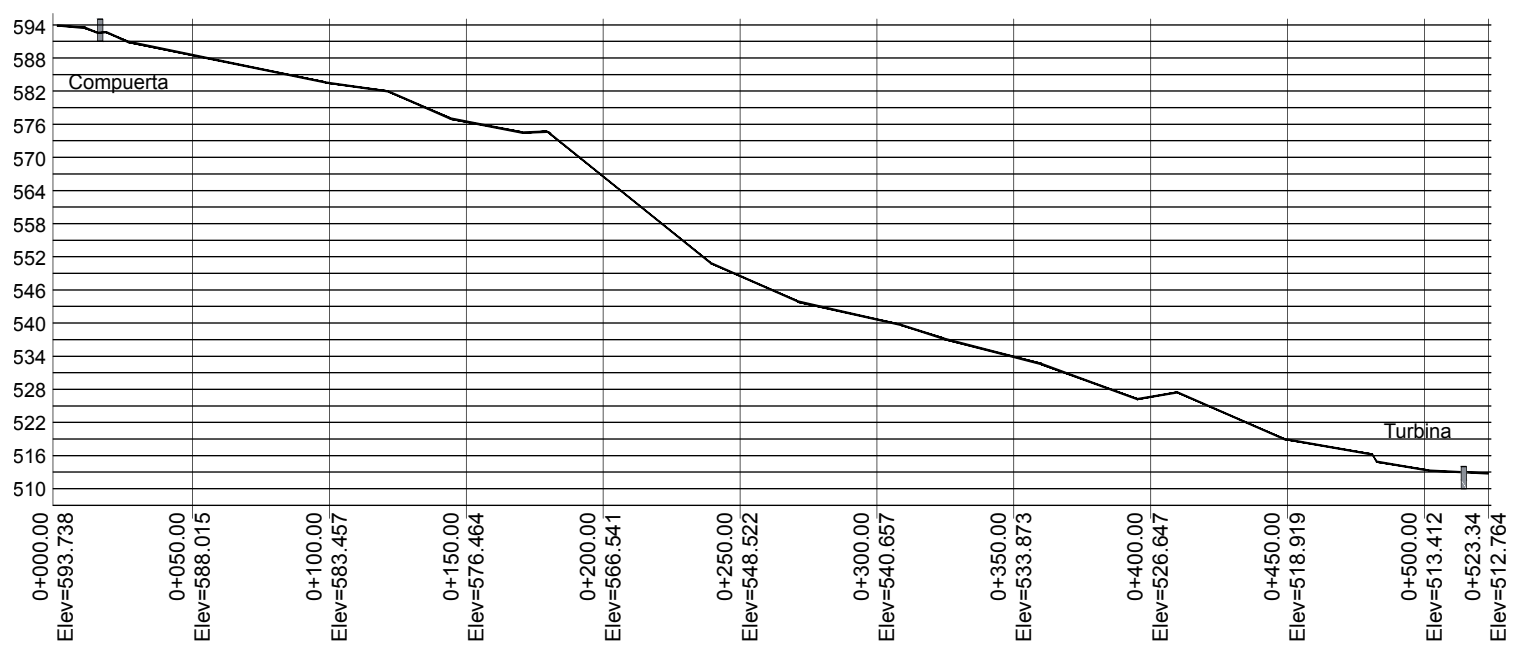

Para permitir la aplicación inmediata del algoritmo propuesto se desarrolló una interfaz gráfica sencilla e intuitiva (mostrada en la Figura 32).

La interfaz permite la introducción directa de los parámetros relevantes, así como la lectura de los datos topográficos directamente desde un fichero excel.

Para cada uno de los dos casos de mejora se ejecutó el algoritmo de optimización y se obtuvieron las soluciones listadas en la Tabla 7. Tras el estudio de las dos propuestas realizadas, los técnicos de FHIA optan por la primera de las dos propuestas de mejora (representada en la Figura 33), para lo que se preparó un plano con el trazado para facilitar las labores de instalación.

De acuerdo con las dos propuestas de mejora adicionales, relativas al equipamiento del sistema, se diseñaron y fabricaron mediante técnicas de fabricación aditiva los modelos de las cucharas (Figura 34), que fueron replicados en acero siguiendo un proceso de fundición en arena verde. 
FIGURA 32. Interfaz gráfica de usuario (GUI) diseñada para facilitar la implementación del algoritmo de optimización

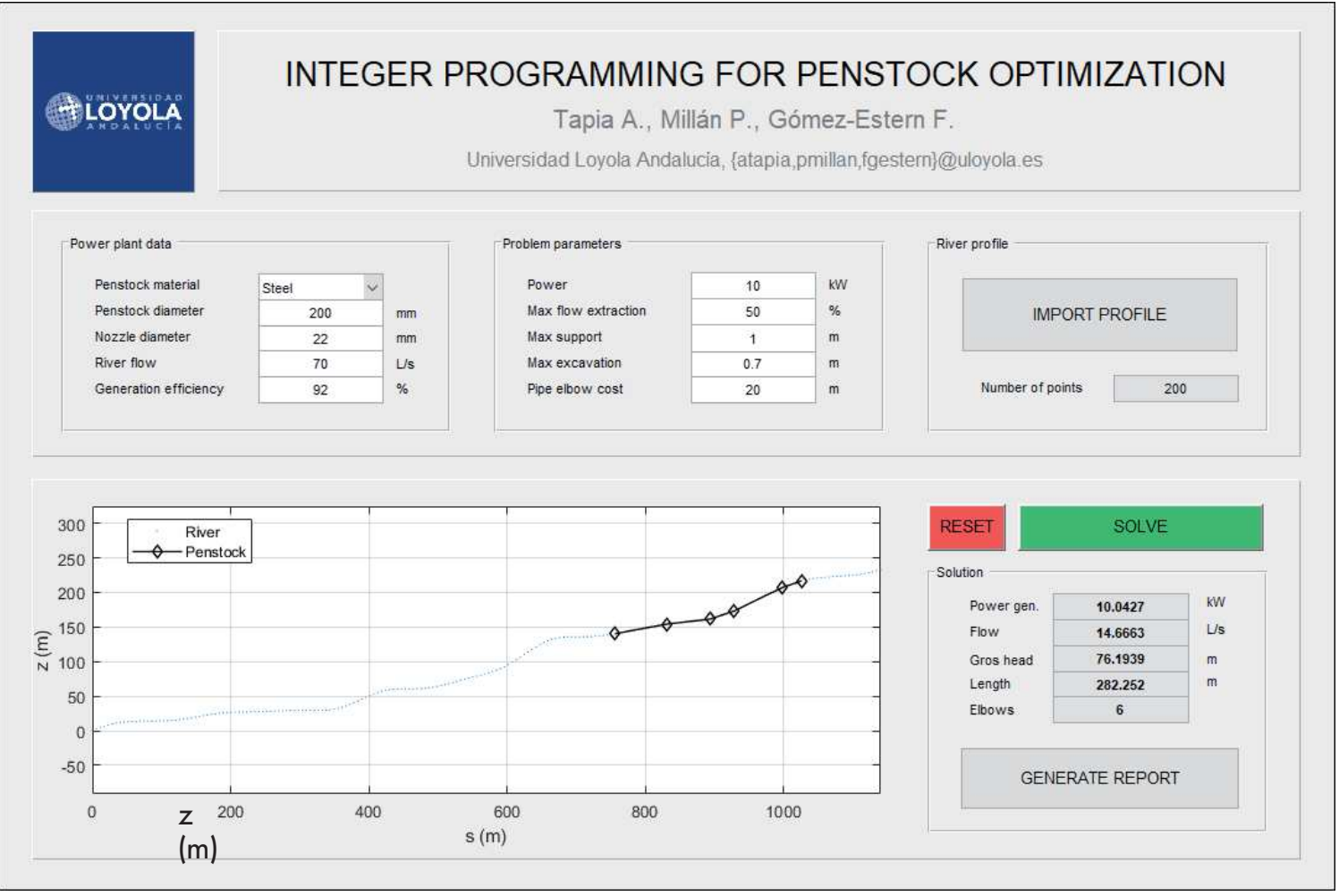

FIGURA 33. Representación de la solución final adoptada

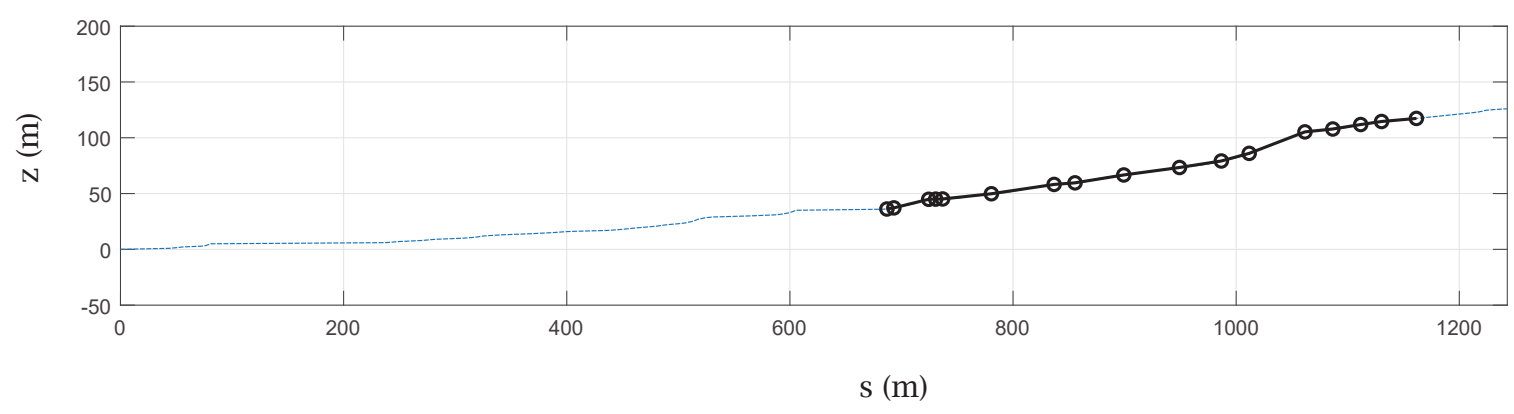


TABLA 7. Soluciones óptimas para los dos casos de mejora de la planta propuesta para San Miguelito

\begin{tabular}{|c|c|c|c|c|c|c|c|}
\hline \multicolumn{4}{|c|}{ Problema } & \multicolumn{3}{c|}{ Solución } \\
\hline Caso & Objetivo & \multicolumn{2}{|c|}{ Restricciones } & $\begin{array}{c}P \\
\mathrm{~kW}\end{array}$ & $\begin{array}{c}H_{\mathrm{g}} \\
\mathrm{m}\end{array}$ & $\begin{array}{c}\mathrm{L} \\
\mathrm{m}\end{array}$ \\
\hline Ref. & - & \multicolumn{2}{|c|}{ Propuesta de FHIA } & 11.423 & 81.130 & 526.691 \\
\hline A & Min $L P$ & $P$ & $\geq$ & Pref & 11.432 & 81.162 & 483.283 \\
\hline B & Max $P$ & LP & $\leq$ & LP,ref & 12.247 & 84.985 & 520.947 \\
\hline
\end{tabular}

\section{FIGURA 34. Modelo de una cuchara Pelton fabricado mediante fabricación aditiva para su posterior réplica en acero mediante fundición en arena}

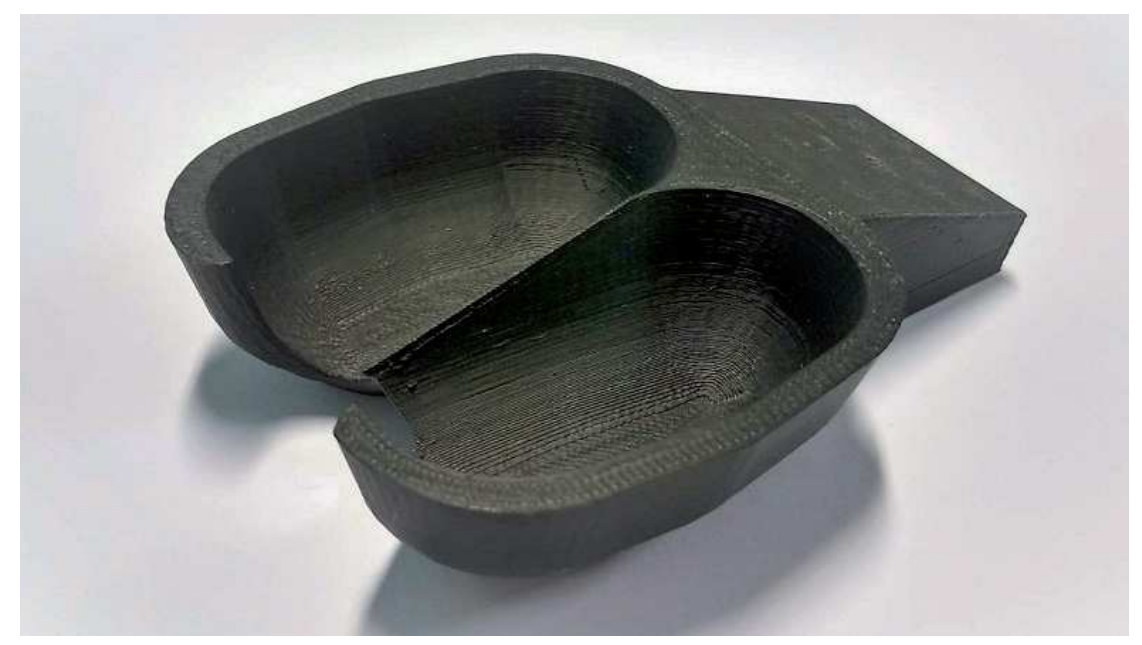

Por último, tras la finalización de la obra civil, se procedió a instalar el sistema de monitorización remota. El sistema instalado dispone de un conjunto de sensores capaces de medir con precisión las variables eléctricas del sistema de generación, transmitiéndolas de forma digital a la comunidad mediante una conducción de fibra óptica. En la comunidad se instaló un pequeño PLC Siemens LOGO (Figura 35) para mostrar de forma sencilla toda la información de la casa de máquinas. Actualmente el sistema lleva más de un año en funcionamiento continuo sin averías, facilitando a los miembros de la comunidad de San Miguelito aprovechar de forma óptima el recurso eléctrico minimizando la necesidad de visitar la casa de máquinas, situada a unos 400 metros de la comunidad. 
Por último, el proyecto finalizó con la sesión de capacitación para los miembros de la comunidad de San Miguelito (Figura 36, donde se formó a los beneficiarios sobre la gestión del nuevo recurso, así como el Reglamento del Proyecto San Miguelito, que hasta el día de hoy ha servido de guía para garantizar la sostenibilidad del proyecto, así como las responsabilidades y derechos de sus beneficiarios.

\section{FIGURA 35. PLC Siemens instalado en la comunidad de San Miguelito}

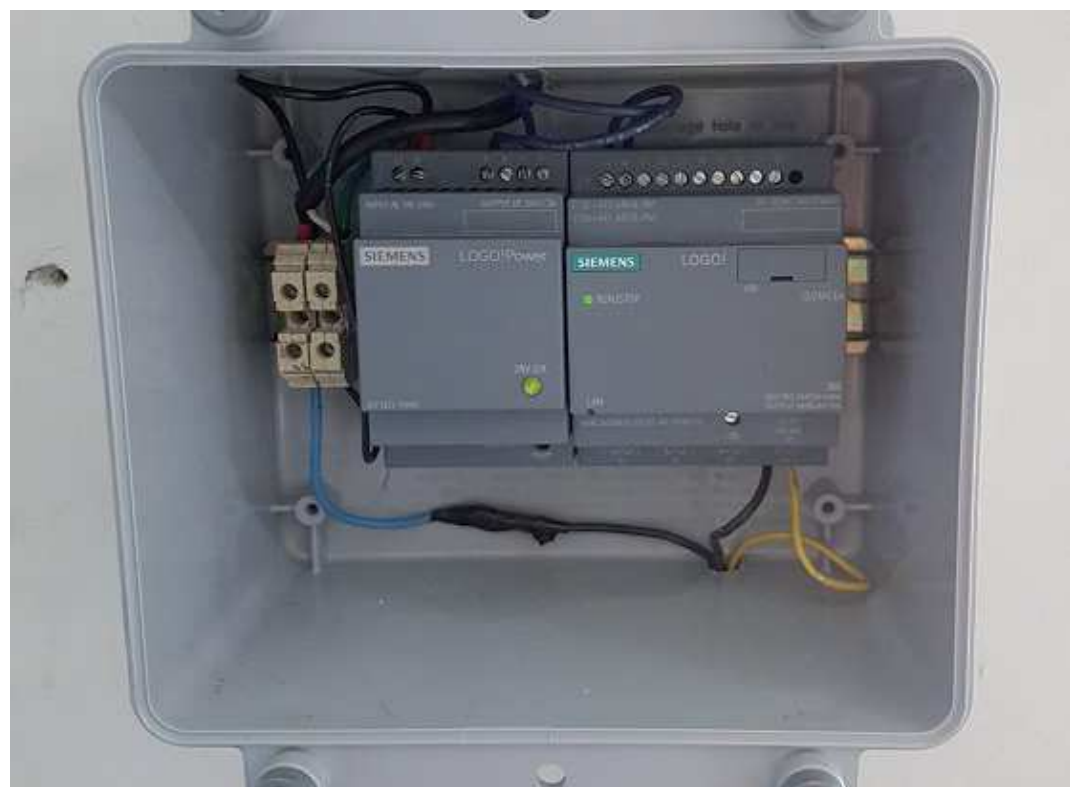

\section{Conclusiones del trabajo}

El presente trabajo resume brevemente los resultados de la investigación llevada a cabo en la Universidad Loyola Andalucía junto con la Fundación ETEA para el Desarrollo y la Cooperación entre 2016 y 2019.

Como parte del proyecto, se desarrolló una estrategia de optimización para el diseño de las plantas micro-hidroeléctricas con aplicación en zonas rurales remotas. La metodología, basada en una primera formulación mediante programación entera y su posterior abordaje mediante algoritmos evolutivos, permite determinar la ubicación óptima para los diferentes elementos que componen la planta, teniendo en cuenta la orografía particular del terreno, así como las necesidades de la comunidad. 
La metodología ha sido utilizada en un proyecto piloto para validar su viabilidad, y se consiguió una reducción notable del coste final de la planta sin requerir recursos adicionales.

Además, a la metodología de diseño se añadieron dos propuestas de mejora, relativas al proceso de fabricación de las turbinas y a la instalación de un sistema económico de monitorización digital del funcionamiento del sistema.

\section{FIGURA 36. Capacitación e inauguración del sistema de generación microhidroeléctrica en San Miguelito}

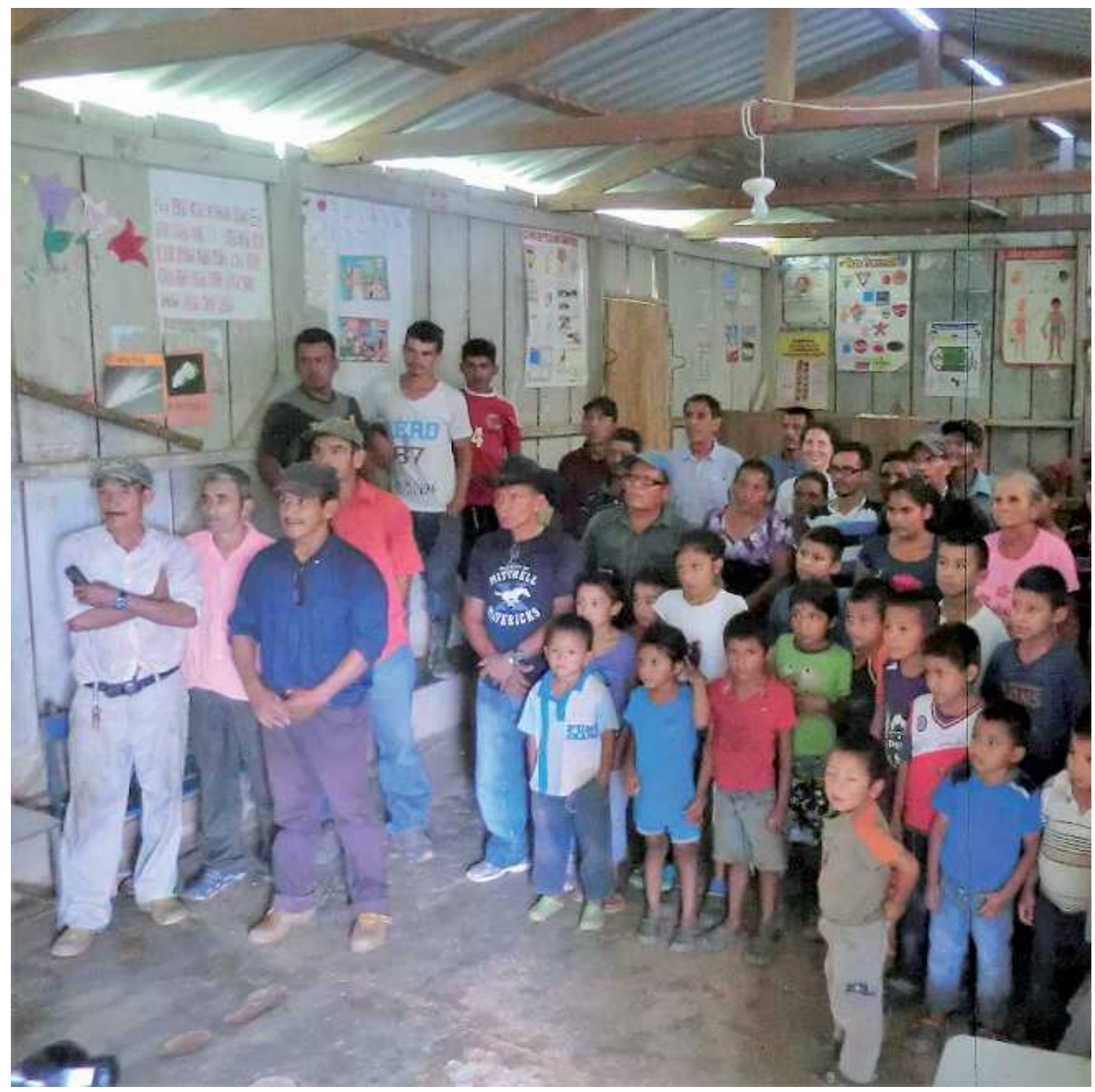


Ambas mejoras fueron implementadas en el proyecto de San Miguelito, y un año después de uso ininterrumpido han demostrado con creces su capacidad de mejorar tanto el funcionamiento como la supervisión y mantenimiento del sistema por parte de la comunidad.

Este motivador proyecto constituye un claro ejemplo de la impetuosa necesidad de trasladar a la realidad los contenidos y resultados de las investigaciones.

\section{Referencias}

Akinyele, D. O. \& RaYUdu, R. K. (2016), "Comprehensive techno-economic and environmental impact study of a localised photovoltaic power system (pps) for off-grid communities". Energy conversion and management, 124:266-279.

Alvarado-Barrios, L., Rodríguez del Nozal, A., Tapia, A., Martínez-Ramos, J. L. \& REINA, D. (2019), "An evolutionary computational approach for the problem of unit commitment and economic dispatch in microgrids under several operation modes". Energies, 12(11):2143.

Anagnostopoulos, J. S. \& Papantonis, D. E. (2007), "Flow Modeling and Runner Design Optimization in Turgo Water Turbines". International Journal of Mechanical, Aerospace, Industrial and Mechatronics Engineering, 1(4):204-209.

BhATAACHARYYA, S. C. (2012), "Energy access programmes and sustainable development: A critical review and analysis". Energy for sustainable development, 16(3):260-271.

ChIEN, TAICHEN \& HU, JIN-LI (2008), "Renewable energy: An efficient mechanism to improve GDP". Energy Policy, 36(8):3045-3052.

CoOK, P. (2011), "Infrastructure, rural electrification and development". Energy for Sustainable Development, 15(3):304-313.

Das, H., Jena, A. K., Nayak, J., Naik, B. \& Behera, H. (2015), "A novel pso based back propagation learning-mlp (pso-bp-mlp) for classification". In Computational Intelligence in Data Mining-Volume 2, pages 461-471. Springer.

Department of Physics, Autonomous National University of Honduras (2008), SWERA Project, 2008a. Evaluation of Wind and Solar potential in Honduras. 
DINCER, I. (2000), "Renewable energy and sustainable development: a crucial review". Renewable and sustainable energy reviews, 4(2):157-175.

Ehteram, M., Karami, H., Mousavi, S.-F., Farzin, S. \& Kisi, O. (2018), "Evaluation of contemporary evolutionary algorithms for optimization in reservoir operation and water supply". Journal of Water Supply: Research and Technology-Aqua, 67(1):54-67.

Flores, W. C., Ojeda, O. A., Flores, M. A. \& Rivas, F. R. (201 1), "Sustainable energy policy in honduras: Diagnosis and challenges". Energy Policy, 39(2):551-562.

GonzÁlez-Eguino, M. (2015), "Energy poverty: An overview". Renewable and Sustainable Energy Reviews, 47:377 - 385.

Gordon, S. B., Bruce, N. G., Grigg, J., Hibberd, P. L., Kurmi, O. P., Lam, K.-B. H., Mortimer, K., Asante, K. P., Balakrishnan, K., Balmes, J. et al. (2014), "Respiratory risks from household air pollution in low and middle income countries". The Lancet Respiratory Medicine, 2(10):823-860.

Haidar, A. M., Senan, M. F., Noman, A. \& Radman, T. (2012), "Utilization of pico hydro generation in domestic and commercial loads". Renewable and Sustainable Energy Reviews, 16(1):518-524.

Ismail, M. S., MoghaVvemi, M. \& Mahla, T. (2013), "Design of an optimized photovoltaic and microturbine hybrid power system for a remote small community: case study of palestine". Energy Conversion and Management, 75:271-281.

KUSAKANA, K. (2015), "Feasibility analysis of river off-grid hydrokinetic systems with pumped hydro storage in rural applications". Energy Conversion and Management, 96:352-362.

LUKE, S. (2009), Essentials of metaheuristics, volume 113. Lulu Raleigh.

MAES, W. H. \& VeRBIST, B. (2012), "Increasing the sustainability of household cooking in developing countries: policy implications". Renewable and Sustainable Energy Reviews, 16(6):4204-4221.

NaYAK, J., NaIK, B., JenA, A., BarIK, R. K. \& Das, H. (2018), "Nature inspired optimizations in cloud computing: applications and challenges". In Cloud Computing for Optimization: Foundations, Applications, and Challenges, pages 1-26. Springer. 
Pereira, M. G., Sena, J. A., Freitas, M. A. V. \& Da Silva, N. F. (2011), "Evaluation of the impact of access to electricity: A comparative analysis of south africa, china, india and brazil". Renewable and Sustainable Energy Reviews, 15(3):1427-1441.

SACHS, J. D. ET AL. (2005), Investing in development: A practical plan to achieve the Millennium Development Goals. Earthscan.

SCHIFFER, H. (2008), "Global energy perspectives until 2050". BWK. EnergieFachmagazin, 60(1-2):49-59.

TapiA, A., Millán, P. \& Gómez-Estern, F. (2018), "Integer programming to optimize micro-hydro power plants for generic river profiles". Renewable energy, 126:905-914.

TAPIA, A., ReINA, D. G. \& GatA, P. M. (2019), An evolutionary computational approach for designing micro hydro power plants. Energies, 12(5).

UNDP (2018), Human development report.

WiJAYATUNGA, P. D. \& ATtALAGE, R. A. (2003), "Analysis of rural household energy supplies in sri lanka: energy efficiency, fuel switching and barriers to expansion". Energy Conversion and Management, 44(7):1123-1130.

WORLD BANK (2018), GDP per capita.

ZelaYA, M. (2009), "Diagnosis of isolated systems and rural electrification". Database of DGE-Honduras. 